\title{
METHOD OF PREDICTION OF RELIABILITY \\ CHARACTERISTICS OF A PUMPING STATION ON THE BASE OF DIAGNOSTIC INFORMATION
}

\section{METODA PREDYKCJI CHARAKTERYSTYK NIEZAWODNOŚCIOWYCH STACJI POMP NA PODSTAWIE INFORMACJI DIAGNOSTYCZNEJ}

\author{
Pawel Lindstedt ${ }^{1}$, Tomasz Sudakowski ${ }^{2}$ \\ 1. Air Force Institute Of Technology \\ Instytut Techniczny Wojsk Lotniczych, ul. Ksiecia Boleslawa 6, 01-494 Warszawa \\ 2. Bialystok Technical University \\ Politechnika Białostocka, ul. Wiejska 45C, 15-351 Bialystok \\ e-mail: ostad@pb.edu.pl, sudak@plusnet.pl
}

\begin{abstract}
It the assessment of technical state in process of opinion of state ability technical object was required (diagnostics) and the reliability state (theory of reliability). It the investigation of relationships in article was conducted between diagnostic state and reliability of technical object. It the innovatory method of use the diagnostic information was introduced in figure "the numbers of diagnostic threshold" to mark of reliability profiles of object. It was passed method the use so the appointed reliability profiles in process of optimization of service given technical object.
\end{abstract}

Key words: object in surroundings, technical state, reliability state, diagnostic threshold, number of crossings of diagnostic threshold

Streszczenie: W procesie oceny stanu zdatności obiektu technicznego wymaga się oceny stanu technicznego (diagnostyka) i stanu niezawodnościowego (teoria niezawodności). W artykule przeprowadzono badania związków między stanem diagnostycznym, a niezawodnosciowym obiektu technicznego. Przedstawiono nowatorską metodę wykorzystania informacji diagnostycznej w postaci „liczb przekroczneń progów diagnostycznych" do wyznaczenia charakterystyk niezawodnościowych obiektu. Podano sposób wykorzystania tak wyznaczonych charakterystyk niezawodnościowych $\mathrm{w}$ procesie optymalizacji obsługi danego obiektu technicznego.

Slowa kluczowe: obiekt w otoczeniu, stan techniczny, stan niezawodnościowy, próg diagnostyczny, liczby przekroczeń progów diagnostycznych. 


\section{METHOD OF PREDICTION OF RELIABILITY \\ CHARACTERISTICS OF A PUMPING STATION ON THE BASE OF DIAGNOSTIC INFORMATION}

\section{Introduction}

In the process of utilisation of a complex technical object (e.g. of pumping station) takes place its destruction, which consists in maladjustment, wear and increase of reliability. Hence, during its standard operation and maintenance necessary is to monitor its adjustment status, technical status and reliability status. Results of the monitoring are the base for synthetic (comprehensive) assessment of object's capability, i.e. ability for correct completion of tasks according to object's purpose.

The assessment of the adjustment status of the object consists in continuous observation of its ability for keeping of correct relation between functional, output signals and input surrounding signals.

The diagnostics consists in continuous observation of changes in the technical status resulting from the relation between diagnostic signals connected with wear of elements, and surrounding signals, both functional and associated.

Research and assessment of reliability of the object consist in continuous acquisition of the knowledge about object defects, which are the border stages of wear of the object and - according to PN-77/N-04005 - translation of observed numbers of defects to reliability characteristics.

Adjustment, diagnostics and reliability are the basic, closely connected elements within the frames of the cybernetic utilisation system. $[1,2,3]$

It was discerned that the observed change of the technical status of the technical object, particularly its threshold and momentary phases, examined according to principles of diagnostics, can become the helpful information about possible defects, which - as it is known - are the base for determination of reliability characteristics. The presented problem has essential importance, since will let determine current reliability characteristics just on the base of the diagnostic information without necessity of waiting for a defect, which is undesirable in the process of utilisation of the technical object. [2,7] 


\section{Description of the object - a pumping station}

The object (pumping station) is shown on the fig. 1 .

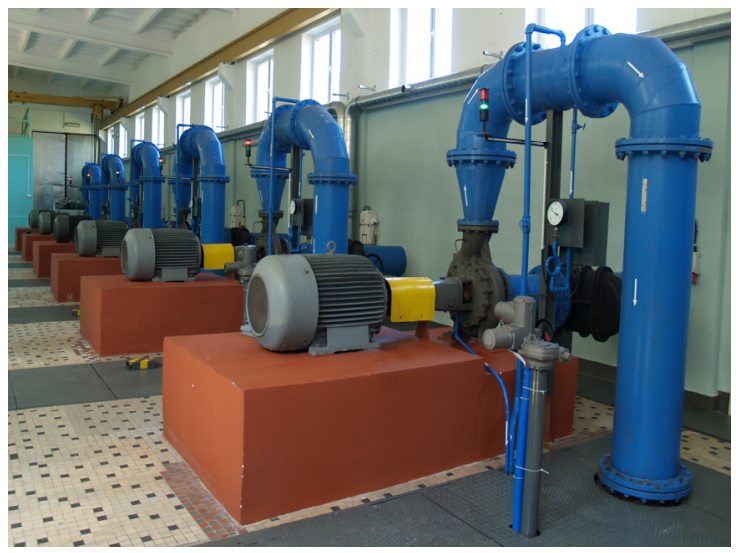

Fig. 1. Pumping station - general view

As the fig. 1 shows, the pumping station consists of six pumping units. Each unit consist of: a three-phase electric motor CELMA type Sg 280 M4 (1), a clutch (2) and a pump fitted with a horizontal shaft type 20A40 with bearings NU (3) - fig. 2.

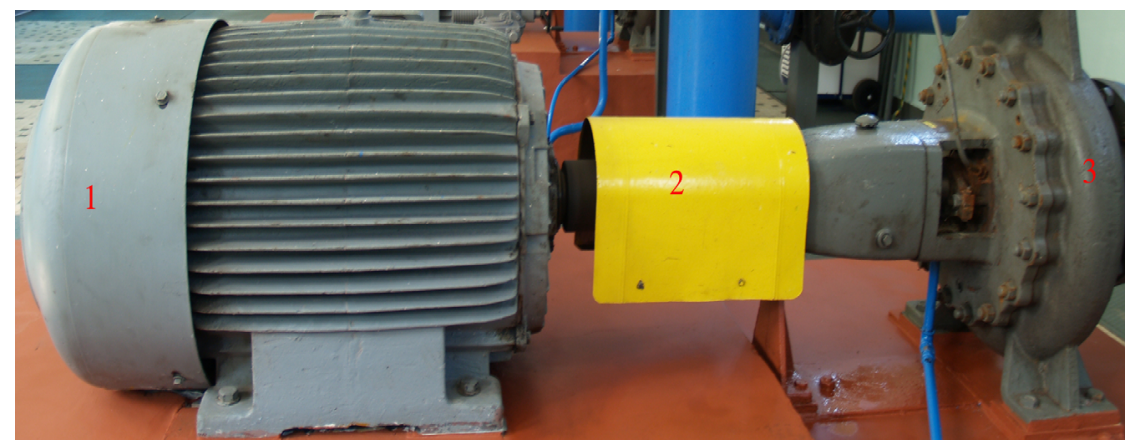

Fig. 2. Pumping unit: 1 - three-phase electric motor CELMA type Sg $280 \mathrm{M} 4$,

2 - clutch, 3 - pumps with horizontal shaft type 20A40 with bearings NU

In the course of continuous (or periodical) utilisation of this complex and expensive object, monitored are characteristic functional, surrounding and associated signals. Their proper processing should give unambiguous answer to the question if the object is correctly used and maintained i.e. if it is correctly identified with respect to its adjustment, diagnostics and reliability. 


\section{Possibilities of comprehensive processing of information about the object in its surrounding}

In the course of maintenance it is necessary to notice that e.g. required "adjustment" was caused by the change in the technical status of the object, which status in the border case becomes the damage status and farther - the danger status. Thus, in the process of utilisation occurs combination of various problems: adjustment, diagnostic and reliability. For comprehensive solution of these problems can be used various configuration of the equation $\mathrm{n}$ of the status. $[3,5,6]$

The adjustment status $a_{R}$ can be calculated from the following equation of the status:

$$
\frac{d N_{U}}{d \Theta}=a_{R} N_{U}+b_{R} N_{D}
$$

where: $\mathrm{N}_{U}$ - resultant of various functional signals (output) and surrounding signals (input), $\mathrm{N}_{\mathrm{D}}$ - resultant of various diagnostic signals connected with wear of the object, $\Theta$ - operation time (Bergson time), $a_{R}$ - adjustment status parameter, $b_{R}$ - parameter of influence of the diagnostic status on the adjustment status.

The technical status of the object can be calculated from the following equation:

$$
\frac{d N_{D}}{d \Theta}=a_{D} N_{D}+b_{D} N_{U}
$$

where additionally: $a_{D}-$ technical status parameter, $b_{D}-$ surrounding influence parameter.

The safety status of the object can be calculated from the following equation:

$$
\frac{d a_{R}}{d \Theta}=a_{B} a_{R}+b_{B} a_{D}
$$

where additionally: $a_{B}-$ safety status parameter, $b_{B}-$ parameter of influence of the technical status on the safety status. 
The reliability status of the object can be calculated from the following equation:

$$
\frac{d a_{D}}{d \Theta}=a_{N} a_{D}+b_{N} a_{R}
$$

where additionally: $a_{N}-$ reliability status parameter, $b_{N}-$ parameter of influence of the adjustment status on the reliability.

The equations $(1-4)$ can form the base for global assessment of the capability status (adjustment, diagnostic, safety and reliability) of the object. This status can be determined quantitatively with help of four parameters: $a_{R}, a_{D}, a_{B}, a_{N}$, and the influence of surrounding - with help of parameters: $b_{R}, b_{D}, b_{B}, i b_{N}$. Special attention should be paid to research of relations between the diagnostic status and the reliability status. However, the serious problem of the research is the fact that relations between functional, diagnostic and associated signals are very complex and difficult to analytical presentation, i.e. these signals are of different physical nature. [3, 4]

\section{New, universal method of forming of information abort object}

The information about the object and its surrounding consists of signals resulting from object's operation within the surrounding (input interference and setting signal, output - functional and control signals) and signals associated with operation (vibrations, wear, friction, cracking, deformation, heating up, corrosion, erosion). These signals, as mentioned above, are of different physical nature, e.g.: interference signals are the white noise but signals connected with wear of elements are the concentration, the granulation of wear products and therefore they are described in different way with respect to their quantity and quality.

The effect of this state of affairs is the fact that research of relations between these different signals is very difficult. The effective solution of this problem is reduction of these signal to the identical universal form, e.g. socalled "number of exceedings of diagnostic thresholds" for these signals (or increments of these signals). The method of reduction of any signal connected with the object, its surrounding or of the associated signal is shown on the fig. 3. [3] 


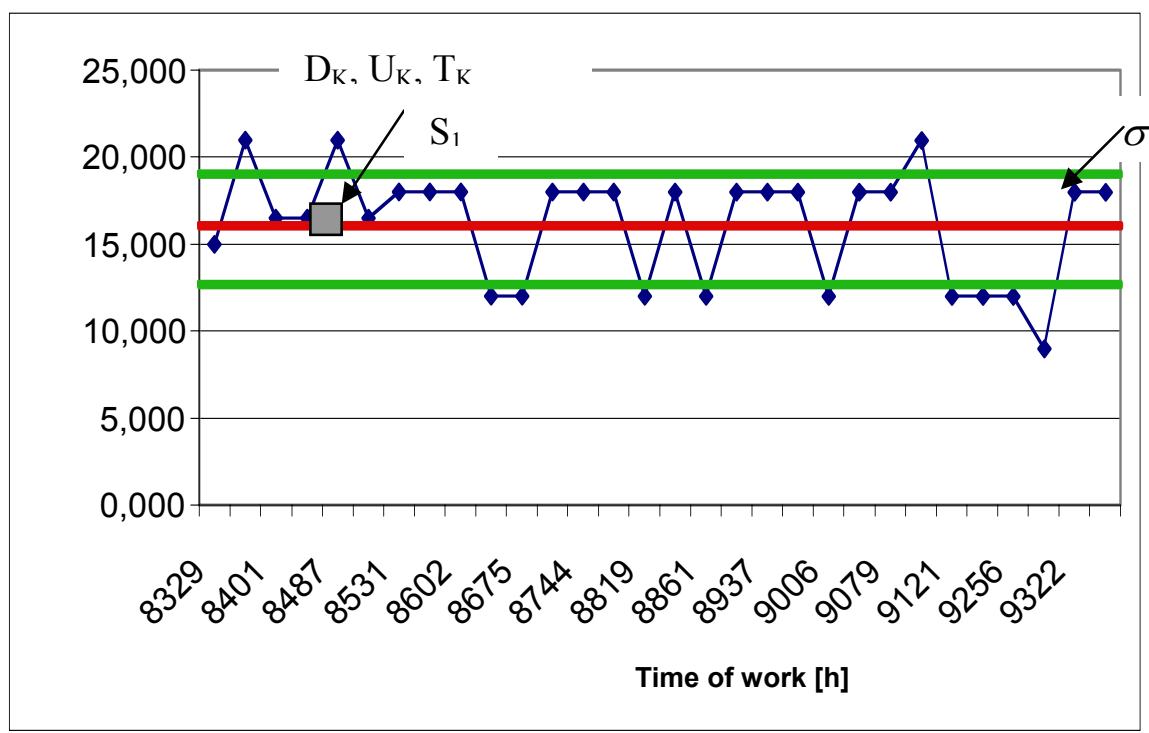

Fig. 3. Reduction of the signal to the form ,number of exceedings of diagnostic thresholds".

$D_{K}$ - diagnostic signal, $U_{K}$ - surrounding signal, $\mathrm{T}_{\mathrm{K}}$ - asscociated signal, $\sigma$ - standard value deviation, $\mathrm{S}_{1}$ - elementary field

The fig. 3. show that each consecutive diagnostic signal $D_{k}$, surrounding signal $U_{k}$ or associated signal $T_{k}$ has respective average values $\mu$ and standard deviation $\sigma$. It is possible to set the value of diagnostic threshold for these signals, e.g. $p_{1}=\mu+0,5 \sigma$ or $p_{2}=\mu+\sigma$ or $p_{3}=\mu+2 \sigma$. The exceeding time of the diagnostic threshold for the signal has the average value $\mu_{t}$ and the standard deviation $\sigma_{t}$. Now defined are elementary exceeding fields of the diagnostic threshold for given signal. Exemplary field values are:

$$
S_{1}=0,5 \sigma \cdot 0,5 \sigma_{t} \text { or } S_{1}=\sigma \cdot \sigma_{t} \text { or } S_{1}=2 \sigma \cdot 2 \sigma_{t} \text { etc. }
$$

The number of exceedings of diagnostic thresholds for individual signals can be calculated from the equation:

$$
n_{k}=\frac{\Sigma A_{i}}{S_{1}}
$$

where: $\mathrm{i}$ - consecutive exceedings of the signal, $\mathrm{A}_{\mathrm{i}}$ - partial field of threshold exceeding for signals, $\mathrm{T}_{\mathrm{K}}, \mathrm{U}_{\mathrm{K}}$. 
The result of such formation (processing) of signals $\mathrm{N}_{\mathrm{D} 0}, \mathrm{~N}_{\mathrm{U} 0}, \mathrm{~N}_{\mathrm{Dk}}, \mathrm{T}_{\mathrm{k}}, \mathrm{U}_{\mathrm{k}}$ ar numbers (dimensionless) $\mathrm{n}_{\mathrm{Dk}}, \mathrm{n}_{\mathrm{Uk}}, \mathrm{n}_{\mathrm{Tk}}$. The signals forming $\mathrm{n}_{\mathrm{Tk}}$ can be coupled with diagnostic signals (vibrations, temperature, etc.) or with surrounding signals (corrosion, erosion). Finally, all signals (without exception) connected with the object and its surrounding can be reduced to two sets $\mathrm{N}_{\mathrm{D}}, \mathrm{N}_{\mathrm{U}}$ of ,numbers of exceedings of diagnostic thresholds" for these signals:

$$
\begin{aligned}
& N_{D}=\sqrt{n_{D_{1}}+n_{D_{2}}^{2}+\ldots+n_{D_{k}}^{2}+n_{T_{1}}^{2}+n_{T_{2}}^{2}+\ldots+n_{T_{k}}^{2}} \\
& N_{U}=\sqrt{n_{U_{1}}+n_{U_{2}}^{2}+\ldots+n_{U_{k}}^{2}+n_{T_{k+1}}^{2}+n_{T_{k+2}}^{2}+\ldots+n_{T_{n}}^{2}}
\end{aligned}
$$

Thus, for each moment $\Theta_{0}, \Theta_{1}, \Theta_{2}$ etc. we get pairs of numbers $\mathrm{N}_{\mathrm{D} 1}, \mathrm{~N}_{\mathrm{U} 1}$; $\mathrm{N}_{\mathrm{D} 2}, \mathrm{~N}_{\mathrm{U} 2}$, etc., one of which is connected with the object, and the other with its surrounding. The result of such formation and arrangement of information is the evident benefit obtained due to possibility of description of relation between signals $\mathrm{N}_{\mathrm{D}}$ and $\mathrm{N}_{\mathrm{U}}$ and ,technical status" of the object with help of the equation of status. The general form of the equation of status is as follows $[6,8]$ :

$$
\frac{d N_{D}}{d \Theta}=a N_{D}+b N_{U}
$$

where: $N_{D}$ - status variable (diagnostic signal), $N_{U}$ - control variable (surrounding), a - technical status parameter, b - control parameter (influence of the surrounding).

The equation of the status connecting the dynamics of the process $\frac{d N_{D}}{d \Theta}$ with this process $\mathrm{N}_{\mathrm{D}}$ and its surrounding $\mathrm{N}_{U}$ is used in automatics, diagnostics and research of reliability depending on needs of these autonomic science areas.

According to the principles of static and dynamic identification [6] from the equation (8) we get:

$$
\begin{aligned}
& N_{D}=\left(-\frac{b}{a}\right) N_{U}=\hat{a} N_{U} \\
& \hat{a}=\frac{\Sigma N_{D i} N_{U i}}{\Sigma N_{U i}^{2}}
\end{aligned}
$$

and:

$$
\frac{\Delta N_{D}}{\Delta \Theta}=a N_{D}+a \hat{a} N_{U}=a\left(N_{D}+\hat{a} N_{U}\right)
$$




$$
a=\frac{\Delta N_{D}}{\Delta \Theta\left(N_{D}+\hat{a} N_{U}\right)}
$$

Calculated parameters, successively negative $\hat{a}$ (static identification $N_{D}=0$ ), then „a“ (dynamic identification) and „, b“ enable evaluation of the object status ,a“ and its dependence from the surrounding „, optimum maintenance the diagnostic knowledge should be supplemented with the knowledge about the reliability status of the object. It has been noticed that monitoring of the parameter "a" can be the base for determination of reliability characteristics.

\section{Relations between changes of technical status and reliability of the object}

In the course of research according to $\mathrm{PN}-77 / \mathrm{N}-04005$ experimentally determined is the estimator (points) of reliability characteristics:

$$
P^{*}(t)=\frac{m(t)}{n}
$$

where: $P^{*}(t)$ - estimator, experimentally determined point of the characteristic of object's deceptiveness, $m(t)$ - number of objects with defects within the time interval $<0, t>, n-$ number of examined objects.

$$
R^{*}(t)=\frac{n(t)}{n}
$$

where: $\mathrm{R}^{*}(\mathrm{t})$ - estimator, experimentally determined point of the characteristic of object's reliability, $n(t)$ - number of objects without defects within the time interval $<0, \mathrm{t}\rangle, \mathrm{n}-$ number of examined objects.

$$
\lambda^{*}(t)=\frac{n(t)-n(t+\Delta t)}{n(t) \Delta t}
$$

where: $\lambda^{*}(t)$ - estimator, experimentally determined point of the characteristic of object's reliability, $\mathrm{n}(\mathrm{t}+\Delta \mathrm{t})$ - number of objects without defects within the time interval $\langle\mathrm{t}+\Delta \mathrm{t}\rangle, \Delta \mathrm{t}$ - examined time interval. 
Points determined with this method form the base for construction of analytical form of the reliability characteristic. According to PN-79/N04031 assumed are following functions of damage distribution: exponential, Weibull's, normal and logarithmic - normal, and its compatibility with determined estimators $\mathrm{R}^{*}(\mathrm{t}), \mathrm{P}^{*}(\mathrm{t}), \lambda^{*}(t)$ is verified according to $\mathrm{PN}-83 / \mathrm{N}$ 01052.07 with help of compatibility tests recommended there: $\chi^{2}$ Pearson, $\lambda$ - Kołmogorow and $\mathrm{W}-$ Shapiro - Wilk.

During calculation of reliability usually determined is also $\mathrm{R}(\mathrm{t})$. The base for calculation of $R(t)$ should be three Basic types of defects: catastrophic, parametric and momentary [7]. During calculation of reliability it is assumed that:

$$
R(t)=R_{a}(t) R_{b}(t) R_{c}(t)
$$

where: $R_{a}(t)$ - probability of correct operation with respect to total, catastrophic defects, $R_{b}(t)$ - probability of correct operation with respect to partial, parametric defects, $\mathrm{R}_{\mathrm{c}}(\mathrm{t})$ - probability of correct operation with respect to momentary, transient defects.

The basic task of maintenance crew is to avoid catastrophic defects $(\mathrm{R}(\mathrm{t})=1)$. From this fact results the conclusion that reliability characteristics should be determined on the base of parametric and momentary defects:

$$
R(t)=R_{b}(t) R_{c}(t)
$$

Basic knowledge abort parametric and momentary defects can be obtained from monitoring of changes of technical status ,a“ (12) determined during diagnostics of the object.

\section{Examples of prediction of reliability characteristics of a pump on the base of diagnostic information}

Numbers of exceedings of the complex diagnostic signal $N_{D}$ and surrounding $\mathrm{N}_{\mathrm{U}}$ and numbers of exceedings of amplitude, vibration frequency nad numbers of exceeding of flow and pressure are shown in the Table 1 and 2. Values of variations and times of occurence form the information about parametric and momentary defects, hence are the base for determination of reliability characteristics. 
Table. 1. Numbers of exceedings of surrounding, diagnostic (functional) signal thresholds together with amplitudes, speeds, vibration frequencies and pumping pressures for the pumping unit No. 3 .

\begin{tabular}{|c|c|c|c|c|c|c|c|}
\hline $\begin{array}{l}\text { Time } \\
\text { of } \\
\text { work }\end{array}$ & $\begin{array}{c}\text { Amplitude } \\
\text { of } \\
\text { vibration }\end{array}$ & $\begin{array}{l}\text { Speed of } \\
\text { vibration }\end{array}$ & $\begin{array}{c}\text { Frequency } \\
\text { of } \\
\text { vibration }\end{array}$ & $\begin{array}{l}\text { Current of } \\
\text { engine }\end{array}$ & $\begin{array}{l}\text { Pressureof } \\
\text { pumping }\end{array}$ & $\begin{array}{c}\text { Complex } \\
\text { diagnosing }\end{array}$ & Surroundings \\
\hline$\Theta$ & $n_{D_{A}}$ & $n_{D_{V}}$ & $n_{D_{f}}$ & $n_{D_{I}}$ & $n_{D_{p}}$ & $\mathrm{~N}_{\mathrm{D}}$ & $\mathrm{N}_{U}$ \\
\hline 8329 & 0.03065 & 0.00063 & 0.00000 & 0.00000 & 0.00000 & 0.03065 & 0.00000 \\
\hline 8354 & 0.00000 & 0.00000 & 0.00000 & 0.00000 & 0.00000 & 0.00000 & 0.00000 \\
\hline 8401 & 0.00701 & 0.01519 & 0.00000 & 0.17986 & 0.00000 & 0.01672 & 0.17986 \\
\hline 8442 & 0.00584 & 0.00000 & 0.03160 & 0.00000 & 0.00000 & 0.03213 & 0.00000 \\
\hline 8487 & 0.01051 & 0.02531 & 0.00000 & 0.26979 & 0.00000 & 0.02741 & 0.26979 \\
\hline 8496 & 0.00000 & 0.00000 & 0.02565 & 0.00000 & 0.10461 & 0.02565 & 0.10461 \\
\hline 8531 & 0.00000 & 0.00000 & 0.00000 & 0.00000 & 0.10461 & 0.00000 & 0.10461 \\
\hline 8578 & 0.00000 & 0.00000 & 0.00000 & 0.00000 & 0.00000 & 0.00000 & 0.00000 \\
\hline 8602 & 0.00467 & 0.00000 & 0.02816 & 0.00000 & 0.00000 & 0.02854 & 0.00000 \\
\hline 8648 & 0.00000 & 0.01519 & 0.04324 & 0.04496 & 0.00000 & 0.04583 & 0.04496 \\
\hline 8675 & 0.00000 & 0.00000 & 0.00000 & 0.00000 & 0.00000 & 0.00000 & 0.00000 \\
\hline 8699 & 0.01751 & 0.00000 & 0.00000 & 0.00000 & 0.00000 & 0.01751 & 0.00000 \\
\hline 8744 & 0.19848 & 0.24588 & 0.08548 & 0.00000 & 0.00000 & 2735 & 0.00000 \\
\hline 8769 & 0.00000 & 0.00000 & 0.07040 & 0.00000 & 0.00000 & 0.07040 & 0.00000 \\
\hline 8819 & 0.00701 & 0.00289 & 0.14733 & 0.00000 & 0.00000 & 0.14753 & 0.00000 \\
\hline 8838 & 0.01637 & 0.00000 & 0.09251 & 0.21697 & 0.00000 & 0.09395 & 0.21697 \\
\hline 8861 & 0.02447 & 0.00726 & 0.00000 & 0.00000 & 0.00000 & 0.02552 & 0.00000 \\
\hline 8909 & 0.00000 & 0.06415 & 0.04412 & 0.20602 & 0.00000 & 0.07786 & 0.20602 \\
\hline 8937 & 0.00000 & 0.05830 & 0.00000 & 0.12656 & 0.00000 & 0.05830 & 0.12656 \\
\hline 8982 & 0.00000 & 0.00000 & 0.00000 & 0.00000 & 0.00000 & 0.00000 & 0.00000 \\
\hline 9006 & 0.00567 & 0.00134 & 0.00000 & 0.00000 & 0.00000 & 0.00583 & 0.00000 \\
\hline 9029 & 0.00000 & 0.00000 & 0.00000 & 0.00000 & 0.00000 & 0.00000 & 0.00000 \\
\hline 9079 & 0.00000 & 0.00000 & 0.00000 & 0.00000 & 0.00000 & 0.00000 & 0.00000 \\
\hline 9097 & 0.00000 & 0.00000 & 0.00000 & 0.00000 & 0.00000 & 0.00000 & 0.00000 \\
\hline 9121 & 0.02149 & 0.01118 & 0.00000 & 0.00000 & 0.00000 & 0.02423 & 0.00000 \\
\hline 9235 & 0.06075 & 0.02959 & 0.00000 & 0.00000 & 0.00000 & 0.06758 & 0.00000 \\
\hline 9256 & 0.03875 & 0.01840 & 0.05274 & 0.00000 & 0.00000 & 0.06798 & 0.00000 \\
\hline 9278 & 0.00000 & 0.00000 & 0.05208 & 0.00000 & 0.00000 & 0.05208 & 0.00000 \\
\hline 9322 & 0.00000 & 0.00000 & 0.00000 & 0.00000 & 0.00000 & 0.00000 & 0.00000 \\
\hline 9333 & 0.00154 & 0.00000 & 0.01140 & 0.00771 & 0.00000 & 0.01150 & 0.00771 \\
\hline
\end{tabular}

Number of exceedings for comprehensive diagnostics $N_{D}$ and surrounding $\mathrm{N}_{U}$ have been calculated from equations (6) and (7). 
Metoda predykcji charakterystyk niezawodnościowych....

Table. 2. Numbers of exceedings of surrounding, diagnostic (functional) signal thresholds together with amplitudes, speeds, vibration frequencies and pumping pressures for the pumping unit No. 4.

\begin{tabular}{|c|c|c|c|c|c|c|c|}
\hline $\begin{array}{c}\text { Time } \\
\text { of } \\
\text { work }\end{array}$ & $\begin{array}{l}\text { Amplitude } \\
\text { of vibration }\end{array}$ & $\begin{array}{l}\text { Speed of } \\
\text { vibration }\end{array}$ & $\begin{array}{l}\text { Frequency } \\
\text { of vibration }\end{array}$ & $\begin{array}{l}\text { Current of } \\
\text { engine }\end{array}$ & $\begin{array}{c}\text { Pressure } \\
\text { of } \\
\text { pumping }\end{array}$ & $\begin{array}{l}\text { Complex } \\
\text { diagnosing }\end{array}$ & Surroundings \\
\hline$\Theta$ & $n_{D_{A}}$ & $n_{D_{V}}$ & $n_{D_{f}}$ & $n_{D_{I}}$ & $n_{D_{p}}$ & $\mathrm{~N}_{\mathrm{D}}$ & $\mathrm{N}_{\mathrm{U}}$ \\
\hline 8315 & 0.00000 & 0.00032 & 0.00000 & 0.00000 & 1.00000 & 0.00032 & 1.00000 \\
\hline 8340 & 0.00000 & 0.01148 & 0.00000 & 0.00000 & 1.00000 & 0.01148 & 1.00000 \\
\hline 8365 & 0.00000 & 0.01148 & 0.00000 & 0.00000 & 1.00000 & 0.01148 & 1.00000 \\
\hline 8437 & 0.05239 & 0.00000 & 0.00000 & 0.00000 & 1.00000 & 0.05239 & 1.00000 \\
\hline 8447 & 0.00000 & 0.00000 & 0.00000 & 0.00000 & 1.00000 & 0.00000 & 1.00000 \\
\hline 8484 & 0.00105 & 0.00000 & 0.00000 & 0.00000 & 1.00000 & 0.00105 & 1.00000 \\
\hline 8509 & 0.00000 & 0.00064 & 0.00000 & 0.58452 & 1.00000 & 0.00064 & 1.15830 \\
\hline 8567 & 0.00000 & 0.00000 & 0.00000 & 0.00000 & 1.00000 & 0.00000 & 1.00000 \\
\hline 8591 & 0.00000 & 0.00510 & 0.23848 & 0.10960 & 1.00000 & 0.23854 & 1.00599 \\
\hline 8615 & 0.05018 & 0.00829 & 0.00000 & 0.00000 & 1.00000 & 0.05086 & 1.00000 \\
\hline 8660 & 0.05018 & 0.00601 & 0.00000 & 0.00000 & 1.00000 & 0.05054 & 1.00000 \\
\hline 8699 & 0.05018 & 0.00601 & 0.00000 & 0.00000 & 1.00000 & 0.05054 & 1.00000 \\
\hline 8735 & 0.00000 & 0.10841 & 0.00000 & 0.00000 & 1.00000 & 0.10841 & 1.00000 \\
\hline 8756 & 0.00000 & 0.00000 & 0.00000 & 0.00000 & 1.00000 & 0.00000 & 1.00000 \\
\hline 8780 & 0.00000 & 0.00000 & 0.06523 & 0.00000 & 1.00000 & 0.06523 & 1.00000 \\
\hline 8826 & 0.00000 & 0.00000 & 0.00000 & 0.00000 & 1.00000 & 0.00000 & 1.00000 \\
\hline 8850 & 0.00116 & 0.00000 & 0.00000 & 0.00000 & 1.00000 & 0.00116 & 1.00000 \\
\hline 8900 & 0.00000 & 0.00000 & 0.00000 & 0.00000 & 1.00000 & 0.00000 & 1.00000 \\
\hline 8924 & 0.00127 & 0.00000 & 0.00375 & 0.00000 & 1.00000 & 0.00396 & 1.00000 \\
\hline 8949 & 0.00000 & 0.00627 & 0.15098 & 0.13437 & 1.00000 & 0.15111 & 1.00899 \\
\hline 8995 & 0.11830 & 0.00000 & 0.00000 & 0.43979 & 1.00000 & 0.11830 & 1.09244 \\
\hline 9017 & 0.09051 & 0.00254 & 0.25169 & 0.05610 & 1.00000 & 0.26748 & 1.00157 \\
\hline 9067 & 0.00022 & 0.00000 & 0.00000 & 0.00000 & 1.00000 & 0.00022 & 1.00000 \\
\hline 9091 & 0.00000 & 0.00000 & 0.01198 & 0.00000 & 1.00000 & 0.01198 & 1.00000 \\
\hline 9115 & 0.00000 & 0.02914 & 0.04849 & 0.29462 & 1.00000 & 0.05657 & 1.04250 \\
\hline 9243 & 0.00000 & 0.02947 & 0.04248 & 0.19593 & 1.00000 & 0.05170 & 1.01901 \\
\hline 9256 & 0.00149 & 0.00000 & 0.00000 & 0.04797 & 1.00000 & 0.00149 & 1.00115 \\
\hline 9338 & 0.00013 & 0.00000 & 0.00000 & 0.00000 & 1.00000 & 0.00013 & 1.00000 \\
\hline 9362 & 0.00080 & 0.00000 & 0.00000 & 0.05029 & 1.00000 & 0.00080 & 1.00126 \\
\hline 9386 & 0.00014 & 0.00000 & 0.00043 & 0.00000 & 1.00000 & 0.00045 & 1.00000 \\
\hline
\end{tabular}

Number of exceedings for comprehensive diagnostics $N_{D}$ and surrounding $\mathrm{N}_{U}$ have been calculated from equations (6) and (7). 
Table. 3. Sum of numbers of exceedings of surrounding, diagnostic (functional) signal thresholds of the pumping unit together with calculated technical status parameter ,a" for the pumping unit No. 3.

\begin{tabular}{|c|c|c|c|c|c|c|}
\hline $\begin{array}{l}\text { Time } \\
\text { of } \\
\text { work }\end{array}$ & $\begin{array}{c}\text { Total of } \\
\text { complex } \\
\text { diagnosing }\end{array}$ & $\begin{array}{c}\text { Total of } \\
\text { surroundings }\end{array}$ & $\Delta \Theta$ & $\Delta N_{D}$ & $\hat{a}$ & $a$ \\
\hline$\Theta$ & $\Sigma N_{D}$ & $\Sigma N_{U}$ & & & & \\
\hline 8329 & 0.03065 & 0.00000 & 8329 & 0.03065 & -0.80973 & 0.00012 \\
\hline 8354 & 0.03065 & 0.00000 & 8354 & 0.00000 & -0.80973 & 0.00000 \\
\hline 8401 & 0.04738 & 0.17986 & 8401 & 0.01672 & -0.80973 & -0.00002 \\
\hline 8442 & 0.07951 & 0.17986 & 8442 & 0.03213 & -0.80973 & -0.00006 \\
\hline 8487 & 0.10691 & 0.44965 & 8487 & 0.02741 & -0.80973 & -0.00001 \\
\hline 8496 & 0.13256 & 0.55426 & 8496 & 0.02565 & -0.80973 & -0.00001 \\
\hline 8531 & 0.13256 & 0.65887 & 8531 & 0.00000 & -0.80973 & 0.00000 \\
\hline 8578 & 0.13256 & 0.65887 & 8578 & 0.00000 & -0.80973 & 0.00000 \\
\hline 8602 & 0.16110 & 0.65887 & 8602 & 0.02854 & -0.80973 & -0.00001 \\
\hline 8648 & 0.20694 & 0.70383 & 8648 & 0.04583 & -0.80973 & -0.00001 \\
\hline 8675 & 0.20694 & 0.70383 & 8675 & 0.00000 & -0.80973 & 0.00000 \\
\hline 8699 & 0.22445 & 0.70383 & 8699 & 0.01751 & -0.80973 & -0.00001 \\
\hline 8744 & 0.55180 & 0.70383 & 8744 & 0.32735 & -0.80973 & -0.00207 \\
\hline 8769 & 0.62220 & 0.70383 & 8769 & 0.07040 & -0.80973 & 0.00015 \\
\hline 8819 & 0.76973 & 0.70383 & 8819 & 0.14753 & -0.80973 & 0.00008 \\
\hline 8838 & 0.86368 & 0.92080 & 8838 & 0.09395 & -0.80973 & 0.00009 \\
\hline 8861 & 0.88920 & 0.92080 & 8861 & 0.02552 & -0.80973 & 0.00002 \\
\hline 8909 & 0.96705 & 1.12682 & 8909 & 0.07786 & -0.80973 & 0.00016 \\
\hline 8937 & 1.02536 & 1.25338 & 8937 & 0.05830 & -0.80973 & 0.00062 \\
\hline 8982 & 1.02536 & 1.25338 & 8982 & 0.00000 & -0.80973 & 0.00000 \\
\hline 9006 & 1.03118 & 1.25338 & 9006 & 0.00583 & -0.80973 & 0.00004 \\
\hline 9029 & 1.03118 & 1.25338 & 9029 & 0.00000 & -0.80973 & 0.00000 \\
\hline 9079 & 1.03118 & 1.25338 & 9079 & 0.00000 & -0.80973 & 0.00000 \\
\hline 9097 & 1.03118 & 1.25338 & 9097 & 0.00000 & -0.80973 & 0.00000 \\
\hline 9121 & 1.05541 & 1.25338 & 9121 & 0.02423 & -0.80973 & 0.00007 \\
\hline 9235 & 1.12299 & 1.25338 & 9235 & 0.06758 & -0.80973 & 0.00007 \\
\hline 9256 & 1.19097 & 1.25338 & 9256 & 0.06798 & -0.80973 & 0.00004 \\
\hline 9278 & 1.24305 & 1.25338 & 9278 & 0.05208 & -0.80973 & 0.00002 \\
\hline 9322 & 1.24305 & 1.25338 & 9322 & 0.00000 & -0.80973 & 0.00000 \\
\hline 9333 & 1.25455 & 1.26109 & 9333 & 0.01150 & -0.80973 & 0.00001 \\
\hline
\end{tabular}

Parameter "a" was marked on basis of dependence (12). 
Metoda predykcji charakterystyk niezawodnościowych....

Table. 4. Sum of numbers of exceedings of surrounding, diagnostic (functional) signal thresholds of the pumping unit together with calculated technical status parameter „a" for the pumping unit No. 4.

\begin{tabular}{|c|c|c|c|c|c|c|}
\hline $\begin{array}{l}\text { Time } \\
\text { of } \\
\text { work }\end{array}$ & $\begin{array}{c}\text { Total of } \\
\text { complex } \\
\text { diagnosing }\end{array}$ & $\begin{array}{c}\text { Total of } \\
\text { surroundings }\end{array}$ & $\Delta \Theta$ & $\Delta N_{D}$ & $\hat{a}$ & $A$ \\
\hline$\Theta$ & $\Sigma N_{D}$ & $\sum N_{U}$ & & & & \\
\hline 8315 & 0.00032 & 1.00000 & 8315 & 0.00032 & -0.04398 & 0.00000 \\
\hline 8340 & 0.01180 & 2.00000 & 8340 & 0.01148 & -0.04398 & -0.00002 \\
\hline 8365 & 0.02328 & 3.00000 & 8365 & 0.01148 & -0.04398 & -0.00001 \\
\hline 8437 & 0.07566 & 4.00000 & 8437 & 0.05239 & -0.04398 & -0.00006 \\
\hline 8447 & 0.07566 & 5.00000 & 8447 & 0.00000 & -0.04398 & 0.00000 \\
\hline 8484 & 0.07671 & 6.00000 & 8484 & 0.00105 & -0.04398 & 0.00000 \\
\hline 8509 & 0.07735 & 7.15830 & 8509 & 0.00064 & -0.04398 & 0.00000 \\
\hline 8567 & 0.07735 & 8.15830 & 8567 & 0.00000 & -0.04398 & 0.00000 \\
\hline 8591 & 0.31589 & 9.16429 & 8591 & 0.23854 & -0.04398 & -0.00032 \\
\hline 8615 & 0.36674 & 10.16429 & 8615 & 0.05086 & -0.04398 & -0.00007 \\
\hline 8660 & 0.41728 & 11.16429 & 8660 & 0.05054 & -0.04398 & -0.00008 \\
\hline 8699 & 0.46782 & 12.16429 & 8699 & 0.05054 & -0.04398 & -0.00009 \\
\hline 8735 & 0.57622 & 13.16429 & 8735 & 0.10841 & -0.04398 & -0.00461 \\
\hline 8756 & 0.57622 & 14.16429 & 8756 & 0.00000 & -0.04398 & 0.00000 \\
\hline 8780 & 0.64146 & 15.16429 & 8780 & 0.06523 & -0.04398 & -0.00029 \\
\hline 8826 & 0.64146 & 16.16429 & 8826 & 0.00000 & -0.04398 & 0.00000 \\
\hline 8850 & 0.64262 & 17.16429 & 8850 & 0.00116 & -0.04398 & 0.00000 \\
\hline 8900 & 0.64262 & 18.16429 & 8900 & 0.00000 & -0.04398 & 0.00000 \\
\hline 8924 & 0.64658 & 19.16429 & 8924 & 0.00396 & -0.04398 & 0.00000 \\
\hline 8949 & 0.79769 & 20.17328 & 8949 & 0.15111 & -0.04398 & -0.00019 \\
\hline 8995 & 0.91598 & 21.26571 & 8995 & 0.11830 & -0.04398 & -0.00068 \\
\hline 9017 & 1.18346 & 22.26728 & 9017 & 0.26748 & -0.04398 & 0.00015 \\
\hline 9067 & 1.18368 & 23.26728 & 9067 & 0.00022 & -0.04398 & 0.00000 \\
\hline 9091 & 1.19567 & 24.26728 & 9091 & 0.01198 & -0.04398 & 0.00001 \\
\hline 9115 & 1.25224 & 25.30978 & 9115 & 0.05657 & -0.04398 & 0.00004 \\
\hline 9243 & 1.30394 & 26.32879 & 9243 & 0.05170 & -0.04398 & 0.00004 \\
\hline 9256 & 1.30543 & 27.32994 & 9256 & 0.00149 & -0.04398 & 0.00000 \\
\hline 9338 & 1.30556 & 28.32994 & 9338 & 0.00013 & -0.04398 & 0.00000 \\
\hline 9362 & 1.30635 & 29.33121 & 9362 & 0.00080 & -0.04398 & 0.00001 \\
\hline 9386 & 1.30681 & 30.33121 & 9386 & 0.00045 & -0.04398 & 0.00000 \\
\hline
\end{tabular}

Parameter "a" was marked on basis of dependence (12). 


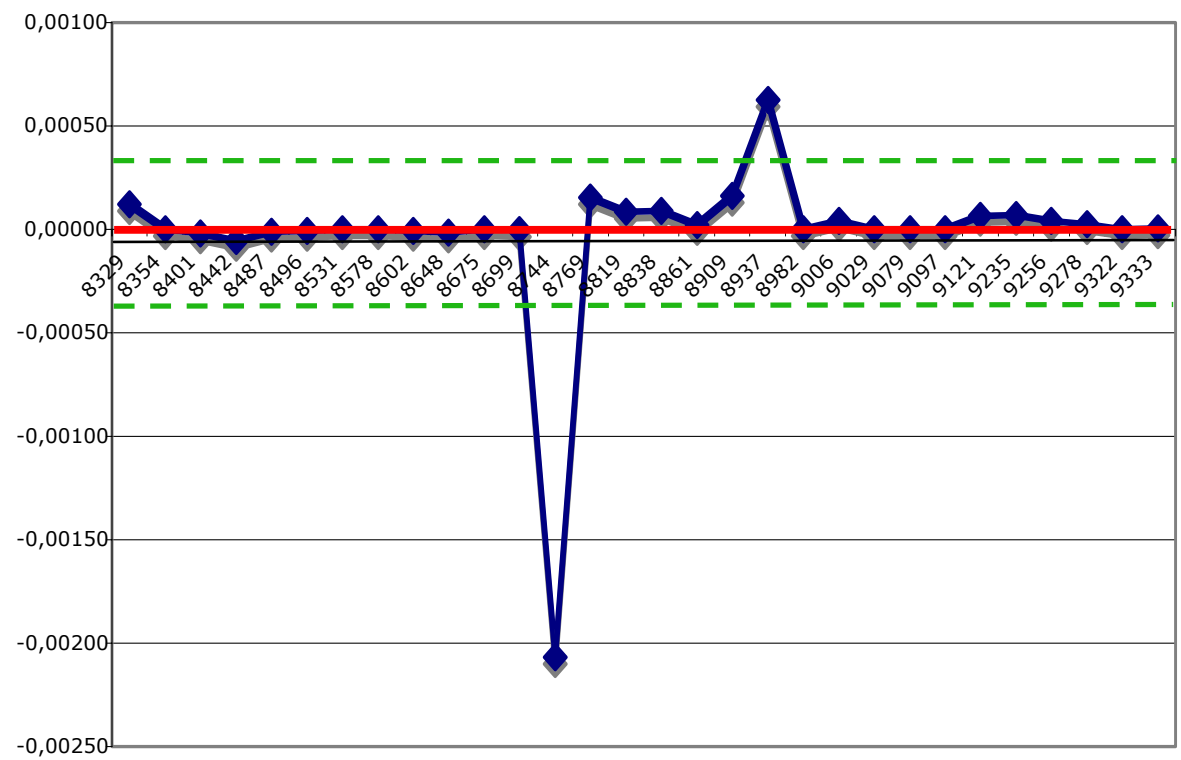

Time of work [h]

Fig. 4. Graph of the parameter „a“ of the pumping unit No. 3 with consideration of the standard deviation (- - - - - - ).

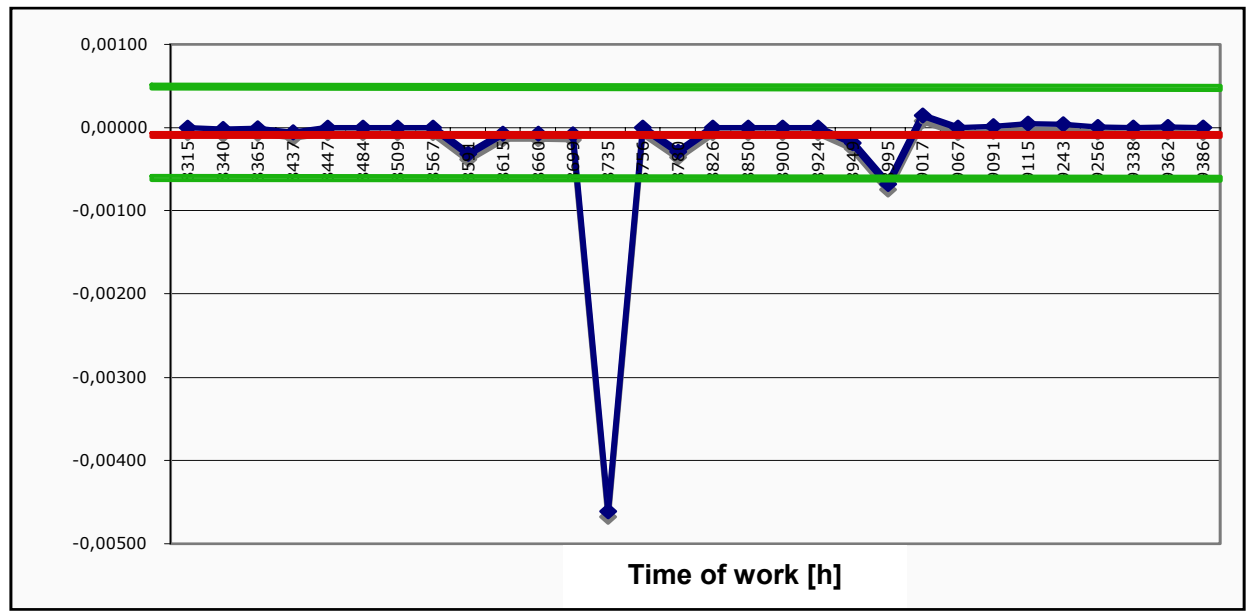

Fig. 5. Graph of the parameter ,a“ of the pumping unit No. 4 with consideration of the standard deviation. 


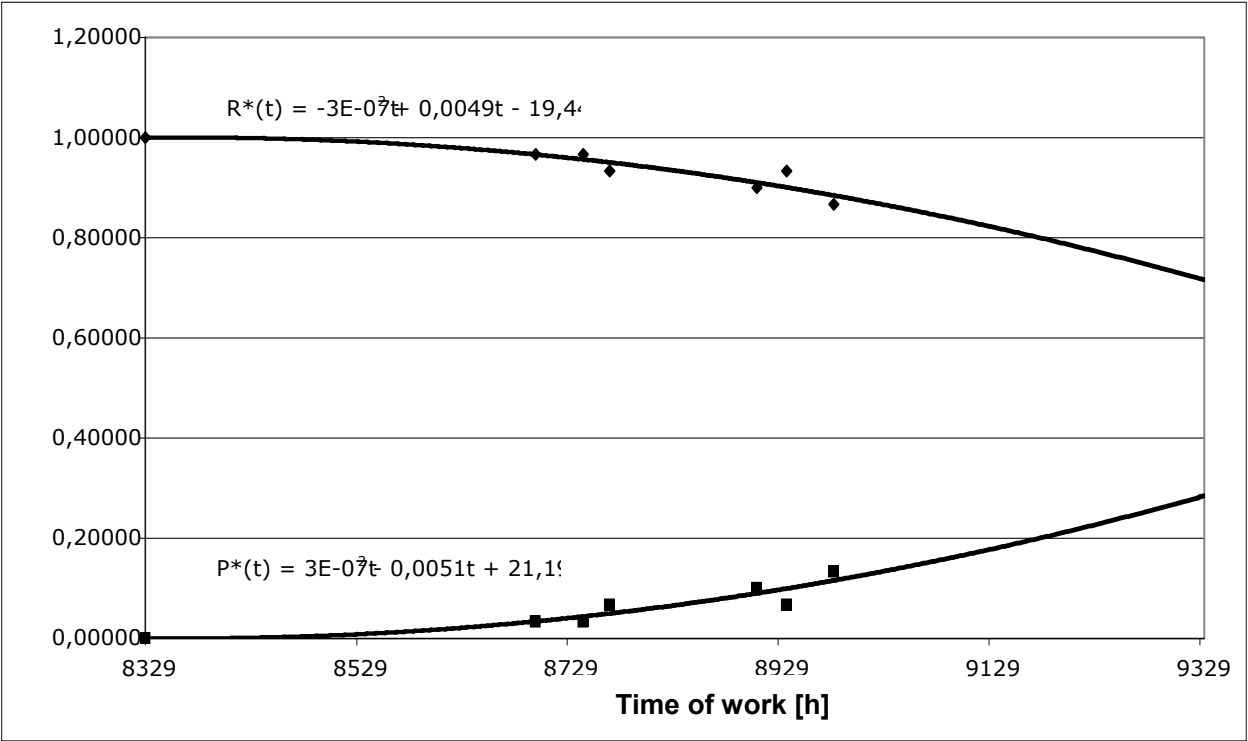

Fig. 6. Graph of the probability of incorrect work the $\mathrm{P}^{*}(\mathrm{t})$ and of the probability of correct work the $\mathrm{R}^{*}(\mathrm{t})$ of the pumping unit No. 3 .

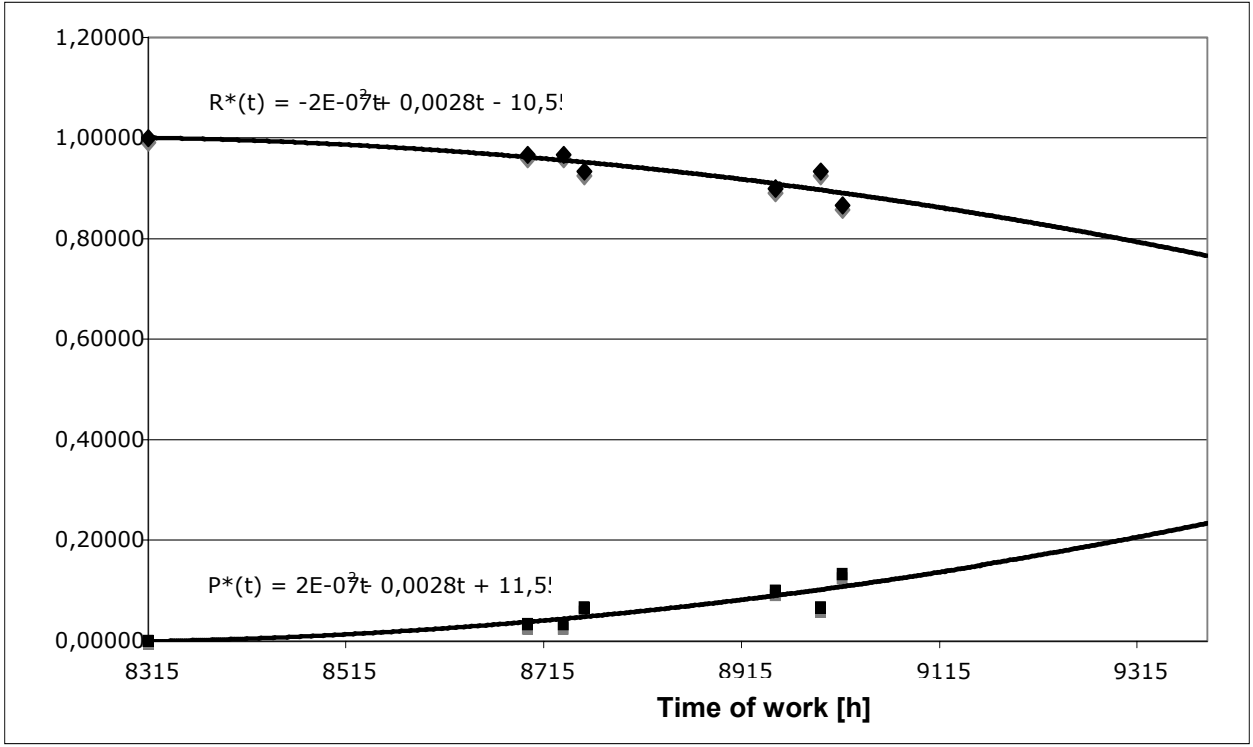

Fig. 6. Graph of the probability of incorrect work the $\mathrm{P}^{*}(\mathrm{t})$ and of the probability of correct work the $\mathrm{R}^{*}(\mathrm{t})$ of the pumping unit No. 4 .

It on basis fig. 5 and it 6 was affirmed that the reliability state and the unreliability state of the pumping unit No. 3 and 4 is similar. Differences 
are minimum because these aggregates be used identically - both work after 24 hour on change.

\section{Summary.}

The reliability profiles are very important information decisive about state of ability of object. The method of their marking are still open problem particularly when technical service does't administer with full information about catastrophic damages, parametral and fading. [7] It in article was introduced innovatory the method to use of diagnostic information (introduced in figure "the numbers of crossings of diagnostic threshold" of usable signals, surroundings and concurrent [4]) to assigment of the reliability profiles. Introduced method is very practical because permits to verify reliability profiles without message about appeared catastrophic damages which can not in process of exploitation in fine mould step out. It was appointed the reliability profiles one should analyse with principles of diagnostics - in connection with profiles of given object in past peaceably and with reliability profiles of different objects of the same type.

\section{Bibiography}

[1] Ashby R. V. - Wstęp do cybernetyki, PWN, Warszawa 1963

[2] Lindstedt P., Sudakowski T. -Prediction the bearing reliability on basis diagnostic information, Journal of KONBIN, 1 (3), 2007, ITWL, Warszawa

[3] Lindstedt P. - Kompleksowa diagnostyka $w$ procesie oceny jakości użytkowania silnika śmigłowcowego $w$ inżynieryjno - lotniczym otoczeniu, „Diagnostyka“ 3 (39) 2006

[4] Lindstedt P., Borowczyk H., Magier J. - Badania możliwości kompleksowego diagnozowania silnika lotniczego na podstawie informacji z metod funkcjonalnej, tribologicznej $i$ wibroakustycznej, Projekt Badawczy KBW Nr 5T12D01122, Sprawozdanie Nr 1371/50, Wyd. ITWL, Warszawa 2003

[5] Paton R., Frank P., Clark R. - Fault diagnostic in dynamic systems. Theory and applications, Cambridge University, Press London 1989

[6] Söderström T., Stoica P. - Identyfikacja systemów, PWN, Warszawa 1997

[7] Stoskow B. S. - Niezawodność elementów i urzqdzeń automatyki, WNT, Warszawa 1973

[8] Wiener N. - Cybernetyka czyli sterowanie i komunikacja w zwierzęciu $i$ maszynie, PWN, Warszawa 1971 


\section{METODA PREDYKCJI CHARAKTERYSTYK NIEZAWODNOŚCIOWYCH STACJI POMP NA PODSTAWIE INFORMACJI DIAGNOSTYCZNEJ}

\section{Wstęp}

W procesie użytkowania złożonego obiektu technicznego (np. stacji pomp) następuje jego destrukcja, która polega na jego rozregulowaniu, zużywaniu i zwiększaniu niezawodności. Stąd wymaga się aby podczas jego standardowego użytkowania i obsługiwania obserwowany był jego stan wyregulowania, stan techniczny i niezawodności. Wyniki tych obserwacji są podstawą do syntetycznej (kompleksowej) oceny zdatności obiektu, tzn. zdolności do prawidłowej realizacji zadań zgodnie z jego przeznaczeniem. Ocena stanu regulacji obiektu polega na ciagłej obserwacji możliwości utrzymania prawidłowej relacji między sygnałami użytkowymi, wyjściowymi, a sygnałami wejściowymi otoczenia.

Diagnostyka polega na ciagłej obserwacji zmian stanu technicznego wynikającego z relacji między sygnałami diagnostycznymi związanymi ze zużywaniem się elementów, a sygnałami otoczenia, użytkowymi i towarzyszącymi.

Badanie i ocena niezawodności obiektu polega na ciagłym gromadzeniu wiedzy o uszkodzeniach obiektu, które są granicznymi stadiami zużywania się obiektu i następnie zgodnie z PN-77/N-04005 przeliczeniu zaobserwowanych liczb uszkodzeń na charakterystyki niezawodnościowe.

Regulacja, diagnostyka i niezawodność są podstawowymi, ściśle ze sobą powiązanymi elementami w ramach cybernetycznego systemu eksploatacji. $[1,2,3]$

Dostrzeżono, że zaobserwowana zmiana stanu technicznego obiektu technicznego, szczególnie jego stadia progowe i chwilowe, badane zgodnie z zasadami diagnostyki, mogą stać się pomocną informacją o możliwych uszkodzeniach, które jak wiadomo są podstawą do wyznaczania charakterystyk niezawodnościowych. Przedstawiony problem ma istotne znaczenie, ponieważ pozwoli wyznaczyć bieżące charakterystyki niezawodnościowe już na podstawie informacji diagnostycznej bez konieczności oczekiwania na zaistnienie niepożądanego w procesie eksploatacji uszkodzenia obiektu technicznego $[2,7]$. 


\section{Opis użytkowanego obiektu - stacji pomp}

Eksploatowany obiekt (stacja pomp) przedstawiono na rys 1.

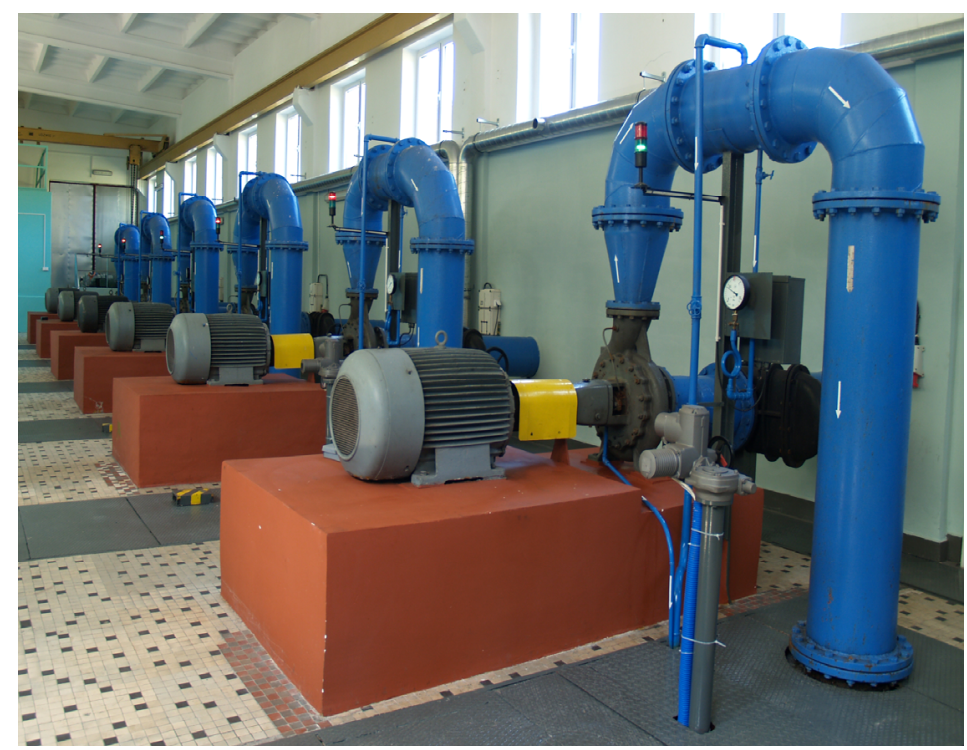

Rys. 1. Widok stacji pomp

Jak widać $\mathrm{z}$ rys. 1 stacja pomp składa się z sześciu zespołów pompowych. Każdy zespół składa się z: trójfazowego silnika elektrycznego CELMA typ Sg 280 M4 (1), sprzęła (2) i pompy o wale poziomym typu $20 \mathrm{~A} 40 \mathrm{z}$ łożyskami typu NU (3) - rys. 2.

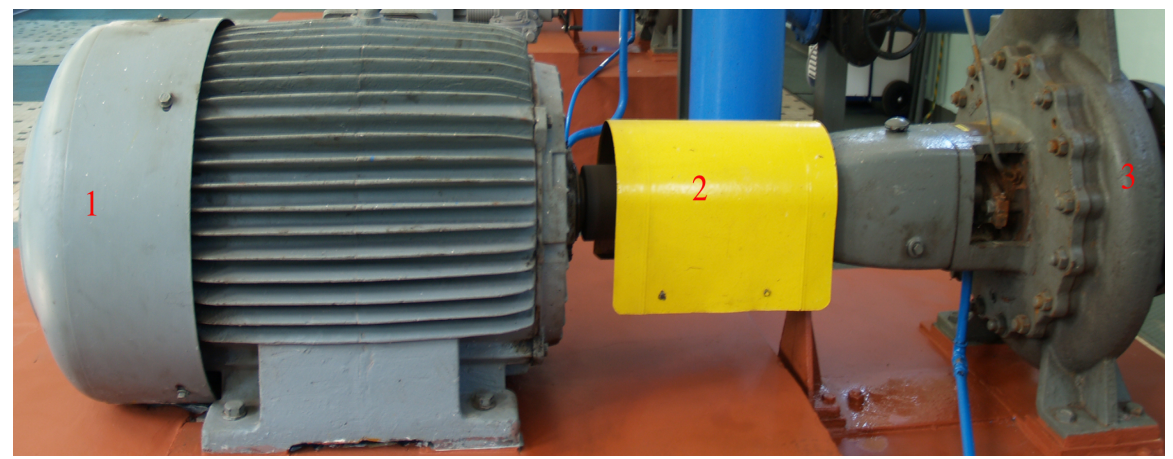

Rys. 2. Zespół pompowy: 1 - trójfazowy silnik elektryczny CELMA typ Sg 280 M4, 2 - sprzegło, 3 - pompy o wale poziomym typu 20A40 $\mathrm{z}$ łożyskami typu NU 
Podczas użytkowanie tego złożonego i kosztownego obiektu technicznego w sposób ciągły (lub okresowy), kontrolowane są ich charakterystyczne sygnały użytkowe, otoczenia i towarzyszące. Ich odpowiednia obróbka powinna dać jednoznaczną odpowiedź na pytanie czy obiekt jest prawidłowo obsługiwany i użytkowany, to znaczy czy jest prawidłowo zidentyfikowany pod względem regulacyjnym, diagnostycznym i niezawodnościowym.

\section{Możliwości kompleksowego przetwarzania informacji o obiekcie w otoczeniu}

Podczas wykonywania czynności obsługowych należy zauważyć, że np. potrzebna ,regulacja“ została wywołana zmianą stanu technicznego obiektu, który to stan $\mathrm{w}$ granicznym przypadku przechodzi $\mathrm{w}$ stan uszkodzenia $\mathrm{i}$ dalej $\mathrm{w}$ stan braku bezpieczeństwa. Zatem $\mathrm{w}$ procesie eksploatacji występuje przeplatanie się różnych problemów: regulacyjnych, diagnostycznych i niezawodnościowych. Do kompleksowego rozwiązania tych problemów można wykorzystać różne konfiguracje równania stanu [3, $5,6]$. Stan regulacji obiektu $a_{R}$ można wyznaczyć $z$ następującego równania stanu:

$$
\frac{d N_{U}}{d \Theta}=a_{R} N_{U}+b_{R} N_{D}
$$

gdzie: $N_{U}$ - wypadkowa różnych sygnałów użytkowych (wyjściowych) $\mathrm{i}$ otoczenia (wejściowych), $\mathrm{N}_{\mathrm{D}}-$ wypadkowa różnych sygnałów diagnostycznych związanych ze zużyciem obiektu, $\Theta$ - czas eksploatacji (bergsonowski), $a_{R}-$ parametr stanu regulacji, $b_{R}$ - parametr oddziaływania stanu diagnostycznego na regulacyjny.

Stan techniczny obiektu można wyznaczyć z następującego równania:

$$
\frac{d N_{D}}{d \Theta}=a_{D} N_{D}+b_{D} N_{U}
$$

gdzie dodatkowo: $a_{D}$ - parametr stanu technicznego obiektu, $b_{D}-$ parametr oddziaływania otoczenia.

Stan bezpieczeństwa obiektu można wyznaczyć z następującego równania:

$$
\frac{d a_{R}}{d \Theta}=a_{B} a_{R}+b_{B} a_{D}
$$


gdzie dodatkowo: $a_{B}-$ parametr stanu bezpieczeństwa, $b_{B}-$ parametr oddziaływania stanu technicznego na stan bezpieczeństwa.

Stan niezawodności obiektu można wyznaczyć z następującego równania:

$$
\frac{d a_{D}}{d \Theta}=a_{N} a_{D}+b_{N} a_{R}
$$

gdzie dodatkowo: $a_{N}-$ parametr stanu niezawodności, $b_{N}-$ parametr oddziaływania stanu regulacji na niezawodność.

Równania (1 - 4), jak widać mogą być podstawą do globalnej oceny stanu zdatności (regulacji, diagnozy, bezpieczeństwa i niezawodności) obiektu. Stan ten może być ilościowo określony za pomocą czterech parametrów: $a_{R}$, $a_{D}, a_{B}, a_{N}, a$ wpływ otoczenia na ten stan za pomocą parametrów: $b_{R}, b_{D}, b_{B}$, i $b_{\mathrm{N}}$. Na szczególną uwagę zasługuje badanie związków między stanem diagnostycznym i niezawodnościowym obiektu. Problemem są tu jednak bardzo złożone i trudne do analitycznego ujęcia relacji między sygnałami użytkowymi, diagnostycznymi i towarzyszącymi, których cechą jest to, że są one różnej natury fizycznej. [3, 4]

\section{Uniwersalny nowy sposób formowania informacji o obiekcie}

Informacją o obiekcie $\mathrm{i}$ jego otoczeniu są sygnały wynikające $\mathrm{z}$ jego działania w otoczeniu (wejściowe - zakłócające i zadające, wyjściowe użytkowe i sterowania) i sygnały towarzyszące temu działaniu (drgania, zużywanie, tarcie, pękanie, deformowanie się, grzanie się, korodowanie, erodowanie). Sygnały te, jak wcześniej wspomniano są różnej natury fizycznej, np.: sygnały zakłócające to szum biały, a sygnały związane z zużywaniem się elementów to koncentracja, granulacja produktów zużywania i dlatego są różnie opisywane pod względem ilościowym i jakościowym. Efektem tego stanu rzeczy jest fakt, że badanie relacji między tymi różnymi sygnałami jest bardzo trudne. Skutecznym rozwiązaniem tego problemu jest sprowadzenie tych różnych sygnałów do jednakowej uniwersalnej postaci, którą mogą być tzw. „liczby przekroczeń progów diagnostycznych" tych sygnałów (lub przyrostów tych sygnałów). Sposób sprowadzania dowolnego sygnału związanego z obiektem, otoczeniem obiektu lub sygnału towarzyszącego przedstawiono na rys. 3 . [3] 


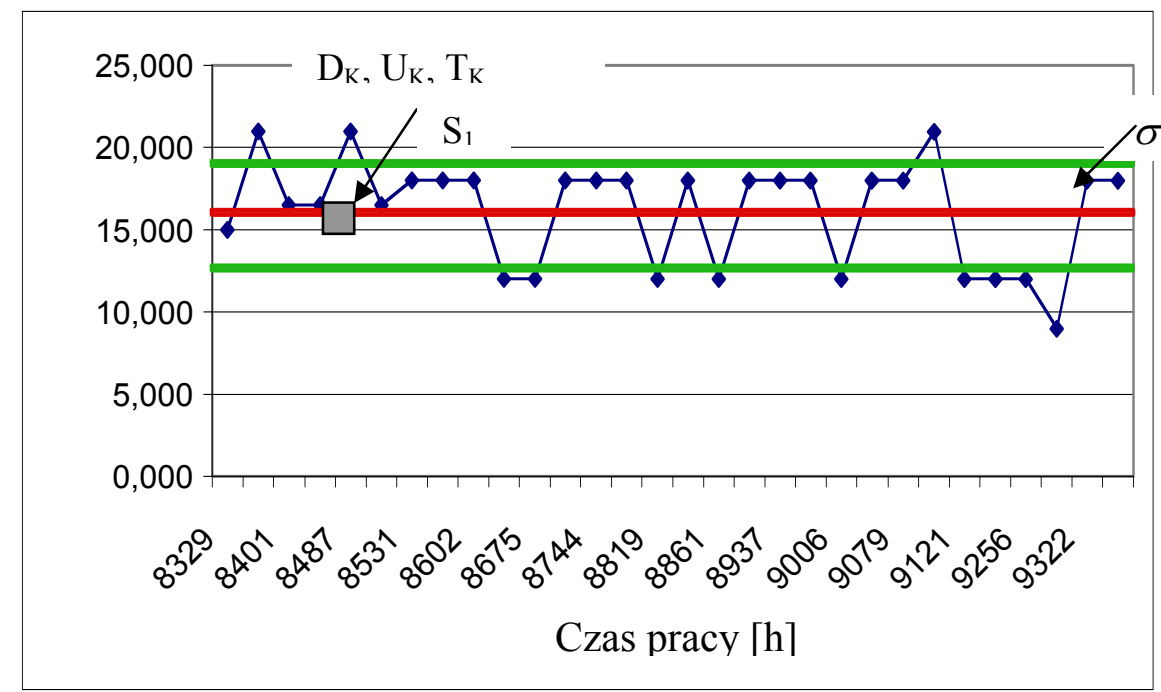

Rys. 3. Sprowadzenie sygnału do postaci „liczb przekroczeń progów diagnostycznych“.

$D_{K}$ - sygnał diagnostyczny, $U_{K}-$ sygnał otoczenia, $\mathrm{T}_{\mathrm{K}}-$ sygnał towarzyszący,

$\sigma$ - odchylenie standardowe wartości, $\mathrm{S}_{1}$ - pole jednostkowe

Z rys. 3. wynika, że każdy kolejny sygnał diagnostyczny $D_{k}$, sygnał otoczenia $U_{k}$ lub sygnał towarzyszący $T_{k}$ ma odpowiadające im wartości średnie $\mu$ i odchylenie standardowe $\sigma$. Dla tych sygnałów można ustalić wartość progu diagnostycznego, np. $p_{1}=\mu+0,5 \sigma$ lub $p_{2}=\mu+\sigma$ lub $p_{3}=\mu+2 \sigma$.Czas przekroczenia przez sygnał jego progu diagnostycznego ma wartość średnią $\mu_{t}$ i odchylenie standardowe $\sigma_{t}$. Następnie ustala się jednostkowe pole przekroczeń przez dany sygnał jego progu diagnostycznego. Przykładowo pola te mogą wynosić:

$S_{1}=0,5 \sigma \cdot 0,5 \sigma_{t}$ lub $S_{1}=\sigma \cdot \sigma_{t}$ lub $S_{1}=2 \sigma \cdot 2 \sigma_{t}$ itd.

Wtedy liczbę przekroczeń progów diagnostycznych dla poszczególnych sygnałów można wyznaczyć z następującej zależności:

$$
n_{k}=\frac{\Sigma A_{i}}{S_{1}}
$$

gdzie: $\mathrm{i}$ - kolejne przekroczenia sygnału, $\mathrm{A}_{\mathrm{i}}$ - pole cząstkowe przekroczenia progu przez sygnały $\mathrm{D}_{\mathrm{K}}, \mathrm{T}_{\mathrm{K}}, \mathrm{U}_{\mathrm{K}}$. 
Rezultatem takiego uformowania (obróbki) sygnałów $\mathrm{N}_{\mathrm{D} 0}, \mathrm{~N}_{\mathrm{U} 0}, \mathrm{~N}_{\mathrm{Dk}}, \mathrm{T}_{\mathrm{k}}, \mathrm{U}_{\mathrm{k}}$ są liczby (bezwymiarowe) $\mathrm{n}_{\mathrm{Dk}}, \mathrm{n}_{\mathrm{Uk}}, \mathrm{n}_{\mathrm{Tk}}$. Sygnały tworzące $\mathrm{n}_{\mathrm{Tk}}$ mogą być skompleksowane z sygnałami diagnostycznymi (drgania, temperatura, itd.) lub $\mathrm{z}$ sygnałami otoczenia (korodowanie, erodowanie). Ostatecznie wszystkie sygnały (bez wyjątku) związane $\mathrm{z}$ obiektem i jego otoczeniem można sprowadzić do dwóch zbiorów $\mathrm{N}_{\mathrm{D}}, \mathrm{N}_{\mathrm{U}}$,liczb przekroczeń progów diagnostycznych" tych różnych sygnałów:

$$
\begin{aligned}
& N_{D}=\sqrt{n_{D_{1}}+n_{D_{2}}^{2}+\ldots+n_{D_{k}}^{2}+n_{T_{1}}^{2}+n_{T_{2}}^{2}+\ldots+n_{T_{k}}^{2}} \\
& N_{U}=\sqrt{n_{U_{1}}+n_{U_{2}}^{2}+\ldots+n_{U_{k}}^{2}+n_{T_{k+1}}^{2}+n_{T_{k+2}}^{2}+\ldots+n_{T_{n}}^{2}}
\end{aligned}
$$

Zatem dla każdej chwili $\Theta_{0}, \Theta_{1}, \Theta_{2}$ itd. otrzymuje się pary liczb $\mathrm{N}_{\mathrm{D} 1}, \mathrm{~N}_{\mathrm{U} 1}$; $\mathrm{N}_{\mathrm{D} 2}, \mathrm{~N}_{\mathrm{U} 2}$, itd., z których jedna związana jest z obiektem, a druga z jego otoczeniem. Efektem takiego uformowania i uporządkowania informacji jest ewidentna korzyść osiaggnięta dzięki możliwości opisania relacji między sygnałami $\mathrm{N}_{\mathrm{D}}$ i $\mathrm{N}_{\mathrm{U}} \mathrm{i}$,stanem technicznym“ obiektu za pomocą równania stanu. Ogólna postać równania stanu jest następująca $[6,8]$ :

$$
\frac{d N_{D}}{d \Theta}=a N_{D}+b N_{U}
$$

gdzie: $\mathrm{N}_{\mathrm{D}}$ - zmienna stanu (sygnał diagnostyczny), $\mathrm{N}_{\mathrm{U}}-$ zmienna sterująca (otoczenie), a - parametr stanu technicznego, b - parametr sterowania (oddziaływanie otoczenia).

Równanie stanu wiążące dynamikę danego procesu $\frac{d N_{D}}{d \Theta} \mathrm{z}$ tym procesem $\mathrm{N}_{\mathrm{D}}$ i jego otoczeniem $\mathrm{N}_{\mathrm{U}}$ jest stosowane $\mathrm{w}$ automatyce, diagnostyce i niezawodności $w$ zależności od potrzeb występujących $\mathrm{w}$ tych autonomicznych dyscyplinach naukowych.

Zgodnie z zasadami identyfikacji statycznej i dynamicznej [6] z równania (8) otrzymuje się:

$$
\begin{gathered}
N_{D}=\left(-\frac{b}{a}\right) N_{U}=\hat{a} N_{U} \\
\hat{a}=\frac{\Sigma N_{D i} N_{U i}}{\Sigma N_{U i}^{2}}
\end{gathered}
$$


oraz:

$$
\begin{aligned}
\frac{\Delta N_{D}}{\Delta \Theta} & =a N_{D}+a \hat{a} N_{U}=a\left(N_{D}+\hat{a} N_{U}\right) \\
a & =\frac{\Delta N_{D}}{\Delta \Theta\left(N_{D}+\hat{a} N_{U}\right)}
\end{aligned}
$$

Wyznaczone parametry kolejno ujemne $\hat{a}$ (identyfikacja statyczna $\hat{N}_{D}=0$ ), a następnie „a“ (identyfikacja dynamiczna) oraz „,b“ pozwalają oceniać stan obiektu „a“ i jego zależność od otoczenia „b“. [3] W optymalnej obsłudze wiedza diagnostyczna powinna być uzupełniona wiedzą o stanie niezawodnościowym obiektu. Dostrzeżono, że obserwacja parametru „a“ może być podstawą do wyznaczania charakterystyk niezawodnościowych.

\section{Związki zmian stanu technicznego z niezawodnością obiektu}

Podczas badań obiektu zgodnie z PN-77/N-04005 eksperymentalnie wyznacza się estymatory (punkty) charakterystyk niezawodności:

$$
P^{*}(t)=\frac{m(t)}{n}
$$

gdzie: $\mathrm{P}^{*}(\mathrm{t})$ - estymator, eksperymentalnie wyznaczony punkt charakterystyki zawodności obiektu, $\mathrm{m}(\mathrm{t})$ - liczba obiektów, które $\mathrm{w}$ przedziale $<0, \mathrm{t}>$ uszkodziły się, $\mathrm{n}$ - liczba badanych obiektów.

$$
R^{*}(t)=\frac{n(t)}{n}
$$

gdzie: $\mathrm{R}^{*}(\mathrm{t})$ - estymator, eksperymentalnie wyznaczony punkt charakterystyki niezawodności obiektu, $\mathrm{n}(\mathrm{t})$ - liczba obiektów, które $\mathrm{w}$ przedziale czasu $<0, \mathrm{t}>$ nie uszkodziły się, $\mathrm{n}$ - liczba badanych obiektów.

$$
\lambda^{*}(t)=\frac{n(t)-n(t+\Delta t)}{n(t) \Delta t}
$$

gdzie: $\quad \lambda^{*}(t)$ - estymator, eksperymentalnie wyznaczony punkt charakterystyki niezawodności obiektu, $\mathrm{n}(\mathrm{t}+\Delta \mathrm{t})$ - liczba obiektów, które $\mathrm{w}$ przedziale czas $\langle\mathrm{t}+\Delta \mathrm{t}\rangle$ nie uszkodziły się, $\Delta \mathrm{t}$ - badany przedział czasu.

Tak wyznaczone punkty są podstawą do ustalenia analitycznej postaci charakterystyki niezawodnościowej. Zgodnie z PN-79/N-04031 przyjmuje się następujące funkcje rozkładu uszkodzeń: wykładniczy, Weibulla, normalny i logarytmiczno - normalny, a ich zgodność z wyznaczonymi estymatorami $\mathrm{R}^{*}(\mathrm{t}), \mathrm{P}^{*}(\mathrm{t}), \lambda^{*}(t)$ sprawdza się zgodnie z PN-83/N-01052.07 
odpowiednio stosując zalecane tam testy zgodności: $\chi^{2}-$ Pearsona, $\lambda$ Kołmogorowa, i W - Shapiro - Wilka.

Przy obliczaniu niezawodności zazwyczaj określa się $\mathrm{R}(\mathrm{t})$. Podstawą do obliczeń $\mathrm{R}(\mathrm{t})$ powinny być trzy podstawowe rodzaje uszkodzeń: katastroficzne, parametryczne i chwilowe [7]. Podczas określania niezawodności przyjmuje się, że:

$$
R(t)=R_{a}(t) R_{b}(t) R_{c}(t)
$$

gdzie: $\mathrm{R}_{\mathrm{a}}(\mathrm{t})$ - prawdopodobieństwo poprawnej pracy ze względu na uszkodzenia całkowite, katastroficzne, $\mathrm{R}_{\mathrm{b}}(\mathrm{t})$ - prawdopodobieństwo poprawnej pracy ze względu na uszkodzenia niecałkowite, parametryczne, $\mathrm{R}_{\mathrm{c}}(\mathrm{t})$ - prawdopodobieństwo poprawnej pracy ze względu na uszkodzenia chwilowe, przemijające.

Podstawowym zadaniem obsługi technicznej jest nie dopuszczenie do wystąpienia uszkodzeń katastroficznych $(\mathrm{R}(\mathrm{t})=1)$. Stąd widać, że charakterystyki niezawodnościowe muszą być wyznaczane na podstawie uszkodzeń parametrycznych i chwilowych:

$$
R(t)=R_{b}(t) R_{c}(t)
$$

Podstawowa wiedza o uszkodzeniach parametrycznych i chwilowych może być uzyskana $\mathrm{z}$ obserwacji zmian stanu technicznego „a“ wyznaczonego podczas diagnozowania obiektu.

\section{Przyklad predykcji charakterystyk niezawodnościowych pompy na podstawie informacji diagnostycznych}

Liczby przekroczeń kompleksowego sygnału diagnostycznego $N_{D} i$ otoczenia $\mathrm{N}_{\mathrm{U}}$ oraz liczby przekroczeń amplitudy, prędkości, częstotliwości drgań i liczby przekroczeń prądu i ciśnienia przedstawiono w tabeli 1 i 2. Wartości zmian i chwile wystapienia ich są informacją o uszkodzeniach parametrycznych i chwilowych. Zatem są podstawą do wyznaczania charakterystyk niezawodnościowych. 
Metoda predykcji charakterystyk niezawodnościowych....

Tabela. 1. Liczby przekroczeń progów sygnałów otoczenia, diagnostycznych (użytkowych) oraz amplitudy, prędkości, częstotliwości drgań, prądu i ciśnienia tłoczenia zespołu pompowego zespołu pompowego $\mathrm{nr} 3$.

\begin{tabular}{|c|c|c|c|c|c|c|c|}
\hline $\begin{array}{l}\text { Czas } \\
\text { pracy }\end{array}$ & $\begin{array}{c}\text { Amplituda } \\
\text { drgań }\end{array}$ & $\begin{array}{l}\text { Prędkość } \\
\text { drgań }\end{array}$ & $\begin{array}{c}\text { Częstotliwość } \\
\text { drgań }\end{array}$ & $\begin{array}{l}\text { Prad } \\
\text { silnika }\end{array}$ & $\begin{array}{l}\text { Ciśnienie } \\
\text { tłoczenia }\end{array}$ & $\begin{array}{c}\text { Diagnozowanie } \\
\text { kompleksowe }\end{array}$ & Otoczenie \\
\hline$\Theta$ & $n_{D_{A}}$ & $n_{D_{V}}$ & $n_{D_{f}}$ & $n_{D_{I}}$ & $n_{D_{p}}$ & $N_{D}$ & $\mathrm{~N}_{U}$ \\
\hline 8329 & 0,03065 & 0,00063 & 0,00000 & 0,00000 & 0,00000 & 0,03065 & 0,00000 \\
\hline 8354 & 0,00000 & 0,00000 & 0,00000 & 0,00000 & 0,00000 & 0,00000 & 0,00000 \\
\hline 8401 & 0,00701 & 0,01519 & 0,00000 & 0,17986 & 0,00000 & 0,01672 & 0,17986 \\
\hline 8442 & 0,00584 & 0,00000 & 0,03160 & 0,00000 & 0,00000 & 0,03213 & 0,00000 \\
\hline 8487 & 0,01051 & 0,02531 & 0,00000 & 0,26979 & 0,00000 & 0,02741 & 0,26979 \\
\hline 8496 & 0,00000 & 0,00000 & 0,02565 & 0,00000 & 0,10461 & 0,02565 & 0,10461 \\
\hline 8531 & 0,00000 & 0,00000 & 0,00000 & 0,00000 & 0,10461 & 0,00000 & 0,10461 \\
\hline 8578 & 0,00000 & 0,00000 & 0,00000 & 0,00000 & 0,00000 & 0,00000 & 0,00000 \\
\hline 8602 & 0,00467 & 0,00000 & 0,02816 & 0,00000 & 0,00000 & 0,02854 & 0,00000 \\
\hline 8648 & 0,00000 & 0,01519 & 0,04324 & 0,04496 & 0,00000 & 0,04583 & 0,04496 \\
\hline 8675 & 0,00000 & 0,00000 & 0,00000 & 0,00000 & 0,00000 & 0,00000 & 0,00000 \\
\hline 8699 & 0,01751 & 0,00000 & 0,00000 & 0,00000 & 0,00000 & 0,01751 & 0,00000 \\
\hline 8744 & 0,19848 & 0,24588 & 0,08548 & 0,00000 & 0,00000 & 0,32735 & 0,00000 \\
\hline 8769 & 0,00000 & 0,00000 & 0,07040 & 0,00000 & 0,00000 & 0,07040 & 0,00000 \\
\hline 8819 & 0,00701 & 0,00289 & 0,14733 & 0,00000 & 0,00000 & 0,14753 & 0,00000 \\
\hline 8838 & 0,01637 & 0,00000 & 0,09251 & 0,21697 & 0,00000 & 0,09395 & 0,21697 \\
\hline 8861 & 0,02447 & 0,00726 & 0,00000 & 0,00000 & 0,00000 & 0,02552 & 0,00000 \\
\hline 8909 & 0,00000 & 0,06415 & 0,04412 & 0,20602 & 0,00000 & 0,07786 & 0,20602 \\
\hline 8937 & 0,00000 & 0,05830 & 0,00000 & 0,12656 & 0,00000 & 0,05830 & 0,12656 \\
\hline 8982 & 0,00000 & 0,00000 & 0,00000 & 0,00000 & 0,00000 & 0,00000 & 0,00000 \\
\hline 9006 & 0,00567 & 0,00134 & 0,00000 & 0,00000 & 0,00000 & 0,00583 & 0,00000 \\
\hline 9029 & 0,00000 & 0,00000 & 0,00000 & 0,00000 & 0,00000 & 0,00000 & 0,00000 \\
\hline 9079 & 0,00000 & 0,00000 & 0,00000 & 0,00000 & 0,00000 & 0,00000 & 0,00000 \\
\hline 9097 & 0,00000 & 0,00000 & 0,00000 & 0,00000 & 0,00000 & 0,00000 & 0,00000 \\
\hline 9121 & 0,02149 & 0,01118 & 0,00000 & 0,00000 & 0,00000 & 0,02423 & 0,00000 \\
\hline 9235 & 0,06075 & 0,02959 & 0,00000 & 0,00000 & 0,00000 & 0,06758 & 0,00000 \\
\hline 9256 & 0,03875 & 0,01840 & 0,05274 & 0,00000 & 0,00000 & 0,06798 & 0,00000 \\
\hline 9278 & 0,00000 & 0,00000 & 0,05208 & 0,00000 & 0,00000 & 0,05208 & 0,00000 \\
\hline 9322 & 0,00000 & 0,00000 & 0,00000 & 0,00000 & 0,00000 & 0,00000 & 0,00000 \\
\hline 9333 & 0,00154 & 0,00000 & 0,01140 & 0,00771 & 0,00000 & 0,01150 & 0,00771 \\
\hline
\end{tabular}

Liczbę przekroczeń diagnozowania kompleksowego $\mathrm{N}_{\mathrm{D}}$ i otoczenia $\mathrm{N}_{\mathrm{U}}$ wyznaczono na podstawie zależności (6) i (7). 
Tabela. 2. Liczby przekroczeń progów sygnałów otoczenia, diagnostycznych (użytkowych) oraz amplitudy, prędkości, częstotliwości drgań, prądu i ciśnienia tłoczenia zespołu pompowego zespołu pompowego $\mathrm{nr} 4$.

\begin{tabular}{|c|c|c|c|c|c|c|c|}
\hline $\begin{array}{l}\text { Czas } \\
\text { pracy }\end{array}$ & $\begin{array}{c}\text { Amplituda } \\
\text { drgań }\end{array}$ & $\begin{array}{c}\text { Prędkość } \\
\text { drgań }\end{array}$ & $\begin{array}{c}\text { Częstotliwość } \\
\text { drgań }\end{array}$ & $\begin{array}{c}\text { Prąd } \\
\text { silnika }\end{array}$ & $\begin{array}{l}\text { Ciśnienie } \\
\text { tłoczenia }\end{array}$ & $\begin{array}{l}\text { Diagnozowanie } \\
\text { kompleksowe }\end{array}$ & Otoczenie \\
\hline$\Theta$ & $n_{D_{A}}$ & $n_{D_{V}}$ & $n_{D_{f}}$ & $n_{D_{I}}$ & $n_{D_{p}}$ & $\mathrm{~N}_{\mathrm{D}}$ & $\mathrm{N}_{\mathrm{U}}$ \\
\hline 8315 & 0,00000 & 0,00032 & 0,00000 & 0,00000 & 1,00000 & 0,00032 & 1,00000 \\
\hline 8340 & 0,00000 & 0,01148 & 0,00000 & 0,00000 & 1,00000 & 0,01148 & 1,00000 \\
\hline 8365 & 0,00000 & 0,01148 & 0,00000 & 0,00000 & 1,00000 & 0,01148 & 1,00000 \\
\hline 8437 & 0,05239 & 0,00000 & 0,00000 & 0,00000 & 1,00000 & 0,05239 & 1,00000 \\
\hline 8447 & 0,00000 & 0,00000 & 0,00000 & 0,00000 & 1,00000 & 0,00000 & 1,00000 \\
\hline 8484 & 0,00105 & 0,00000 & 0,00000 & 0,00000 & 1,00000 & 0,00105 & 1,00000 \\
\hline 8509 & 0,00000 & 0,00064 & 0,00000 & 0,58452 & 1,00000 & 0,00064 & 1,15830 \\
\hline 8567 & 0,00000 & 0,00000 & 0,00000 & 0,00000 & 1,00000 & 0,00000 & 1,00000 \\
\hline 8591 & 0,00000 & 0,00510 & 0,23848 & 0,10960 & 1,00000 & 0,23854 & 1,00599 \\
\hline 8615 & 0,05018 & 0,00829 & 0,00000 & 0,00000 & 1,00000 & 0,05086 & 1,00000 \\
\hline 8660 & 0,05018 & 0,00601 & 0,00000 & 0,00000 & 1,00000 & 0,05054 & 1,00000 \\
\hline 8699 & 0,05018 & 0,00601 & 0,00000 & 0,00000 & 1,00000 & 0,05054 & 1,00000 \\
\hline 8735 & 0,00000 & 0,10841 & 0,00000 & 0,00000 & 1,00000 & 0,10841 & 1,00000 \\
\hline 8756 & 0,00000 & 0,00000 & 0,00000 & 0,00000 & 1,00000 & 0,00000 & 1,00000 \\
\hline 8780 & 0,00000 & 0,00000 & 0,06523 & 0,00000 & 1,00000 & 0,06523 & 1,00000 \\
\hline 8826 & 0,00000 & 0,00000 & 0,00000 & 0,00000 & 1,00000 & 0,00000 & 1,00000 \\
\hline 8850 & 0,00116 & 0,00000 & 0,00000 & 0,00000 & 1,00000 & 0,00116 & 1,00000 \\
\hline 8900 & 0,00000 & 0,00000 & 0,00000 & 0,00000 & 1,00000 & 0,00000 & 1,00000 \\
\hline 8924 & 0,00127 & 0,00000 & 0,00375 & 0,00000 & 1,00000 & 0,00396 & 1,00000 \\
\hline 8949 & 0,00000 & 0,00627 & 0,15098 & 0,13437 & 1,00000 & 0,15111 & 1,00899 \\
\hline 8995 & 0,11830 & 0,00000 & 0,00000 & 0,43979 & 1,00000 & 0,11830 & 1,09244 \\
\hline 9017 & 0,09051 & 0,00254 & 0,25169 & 0,05610 & 1,00000 & 0,26748 & 1,00157 \\
\hline 9067 & 0,00022 & 0,00000 & 0,00000 & 0,00000 & 1,00000 & 0,00022 & 1,00000 \\
\hline 9091 & 0,00000 & 0,00000 & 0,01198 & 0,00000 & 1,00000 & 0,01198 & 1,00000 \\
\hline 9115 & 0,00000 & 0,02914 & 0,04849 & 0,29462 & 1,00000 & $\mathbf{0 , 0 5 6 5 7}$ & 1,04250 \\
\hline 9243 & 0,00000 & 0,02947 & 0,04248 & 0,19593 & 1,00000 & 0,05170 & 1,01901 \\
\hline 9256 & 0,00149 & 0,00000 & 0,00000 & 0,04797 & 1,00000 & 0,00149 & 1,00115 \\
\hline 9338 & $\mathbf{0 , 0 0 0 1 3}$ & 0,00000 & 0,00000 & 0,00000 & 1,00000 & 0,00013 & 1,00000 \\
\hline 9362 & 0,00080 & 0,00000 & 0,00000 & 0,05029 & 1,00000 & 0,00080 & 1,00126 \\
\hline 9386 & 0,00014 & 0,00000 & 0,00043 & 0,00000 & 1,00000 & 0,00045 & 1,00000 \\
\hline
\end{tabular}

Liczbę przekroczeń diagnozowania kompleksowego $\mathrm{N}_{\mathrm{D}}$ i otoczenia $\mathrm{N}_{\mathrm{U}}$ wyznaczono na podstawie zależności (6) i (7). 
Metoda predykcii charakterystyk niezawodnościowych....

Tabela. 3. Suma liczb przekroczeń progów sygnałów otoczenia, diagnostycznych (użytkowych) zespołu pompowego z wyznaczonym parametrem stanu technicznego ,a“" zespołu pompowego nr 3.

\begin{tabular}{|c|c|c|c|c|c|c|}
\hline $\begin{array}{l}\text { Czas } \\
\text { pracy }\end{array}$ & $\begin{array}{c}\text { Suma } \\
\text { diagnozowania } \\
\text { kompleksowego }\end{array}$ & $\begin{array}{c}\text { Suma } \\
\text { otoczenia }\end{array}$ & $\Delta \Theta$ & $\Delta N_{D}$ & $\hat{a}$ & $\mathrm{a}$ \\
\hline$\Theta$ & $\Sigma N_{D}$ & $\sum N_{U}$ & & & & \\
\hline 8329 & 0,03065 & 0,00000 & 8329 & 0,03065 & $-0,80973$ & 0,00012 \\
\hline 8354 & 0,03065 & 0,00000 & 8354 & 0,00000 & $-0,80973$ & 0,00000 \\
\hline 8401 & 0,04738 & 0,17986 & 8401 & 0,01672 & $-0,80973$ & $-0,00002$ \\
\hline 8442 & 0,07951 & 0,17986 & 8442 & $\mathbf{0 , 0 3 2 1 3}$ & $-0,80973$ & $-0,00006$ \\
\hline 8487 & 0,10691 & 0,44965 & 8487 & 0,02741 & $-0,80973$ & $-0,00001$ \\
\hline 8496 & 0,13256 & 0,55426 & 8496 & 0,02565 & $-0,80973$ & $-0,00001$ \\
\hline 8531 & 0,13256 & $0, \mathbf{6 5 8 8 7}$ & 8531 & 0,00000 & $-0,80973$ & 0,00000 \\
\hline 8578 & 0,13256 & $\mathbf{0 , 6 5 8 8 7}$ & 8578 & 0,00000 & $-0,80973$ & 0,00000 \\
\hline 8602 & 0,16110 & $\mathbf{0 , 6 5 8 8 7}$ & 8602 & 0,02854 & $-0,80973$ & $-0,00001$ \\
\hline 8648 & 0,20694 & 0,70383 & 8648 & $\mathbf{0 , 0 4 5 8 3}$ & $-0,80973$ & $-0,00001$ \\
\hline 8675 & 0,20694 & 0,70383 & 8675 & 0,00000 & $-0,80973$ & 0,00000 \\
\hline 8699 & 0,22445 & 0,70383 & 8699 & 0,01751 & $-0,80973$ & $\begin{array}{l}-0,00001 \\
\end{array}$ \\
\hline 8744 & 0,55180 & 0,70383 & 8744 & 0,32735 & $-0,80973$ & $\mathbf{- 0 , 0 0 2 0 7}$ \\
\hline 8769 & 0,62220 & 0,70383 & 8769 & 0,07040 & $-0,80973$ & 0,00015 \\
\hline 8819 & 0,76973 & 0,70383 & 8819 & 0,14753 & $-0,80973$ & 0,00008 \\
\hline 8838 & 0,86368 & 0,92080 & 8838 & 0,09395 & $-0,80973$ & 0,00009 \\
\hline 8861 & 0,88920 & 0,92080 & 8861 & 0,02552 & $-0,80973$ & 0,00002 \\
\hline 8909 & 0,96705 & 1,12682 & 8909 & $\mathbf{0 , 0 7 7 8 6}$ & $-0,80973$ & 0,00016 \\
\hline 8937 & 1,02536 & 1,25338 & 8937 & 0,05830 & $-0,80973$ & 0,00062 \\
\hline 8982 & 1,02536 & 1,25338 & 8982 & 0,00000 & $-0,80973$ & 0,00000 \\
\hline 9006 & 1,03118 & 1,25338 & 9006 & 0,00583 & $-0,80973$ & 0,00004 \\
\hline 9029 & 1,03118 & 1,25338 & 9029 & 0,00000 & $-0,80973$ & 0,00000 \\
\hline 9079 & 1,03118 & 1,25338 & 9079 & 0,00000 & $-0,80973$ & 0,00000 \\
\hline 9097 & 1,03118 & 1,25338 & 9097 & 0,00000 & $-0,80973$ & 0,00000 \\
\hline 9121 & 1,05541 & 1,25338 & 9121 & 0,02423 & $-0,80973$ & 0,00007 \\
\hline 9235 & 1,12299 & 1,25338 & 9235 & 0,06758 & $-0,80973$ & 0,00007 \\
\hline 9256 & 1,19097 & 1,25338 & 9256 & 0,06798 & $-0,80973$ & 0,00004 \\
\hline 9278 & 1,24305 & 1,25338 & 9278 & 0,05208 & $-0,80973$ & 0,00002 \\
\hline 9322 & 1,24305 & 1,25338 & 9322 & 0,00000 & $-0,80973$ & 0,00000 \\
\hline 9333 & 1,25455 & 1,26109 & 9333 & 0,01150 & $-0,80973$ & 0,00001 \\
\hline
\end{tabular}

Parametr „a“" wyznaczono na podstawie zależności (12). 
Tabela. 4. Suma liczb przekroczeń progów sygnałów otoczenia, diagnostycznych (użytkowych) zespołu pompowego z wyznaczonym parametrem stanu technicznego ,a“" zespołu pompowego nr 4.

\begin{tabular}{|c|c|c|c|c|c|c|}
\hline $\begin{array}{l}\text { Czas } \\
\text { pracy }\end{array}$ & $\begin{array}{c}\text { Suma } \\
\text { diagnozowania } \\
\text { kompleksowego }\end{array}$ & $\begin{array}{c}\text { Suma } \\
\text { otoczenia }\end{array}$ & $\Delta \Theta$ & $\Delta N_{D}$ & $\hat{a}$ & $\mathrm{a}$ \\
\hline$\Theta$ & $\sum N_{D}$ & $\Sigma N_{U}$ & & & & \\
\hline 8315 & $\mathbf{0 , 0 0 0 3 2}$ & 1,00000 & 8315 & $\mathbf{0 , 0 0 0 3 2}$ & $-0,04398$ & 0,00000 \\
\hline 8340 & 0,01180 & 2,00000 & 8340 & 0,01148 & $-0,04398$ & $-0,00002$ \\
\hline 8365 & 0,02328 & 3,00000 & 8365 & 0,01148 & $-0,04398$ & $-0,00001$ \\
\hline 8437 & 0,07566 & 4,00000 & 8437 & $\mathbf{0 , 0 5 2 3 9}$ & $-0,04398$ & $-0,00006$ \\
\hline 8447 & 0,07566 & 5,00000 & 8447 & 0,00000 & $-0,04398$ & 0,00000 \\
\hline 8484 & 0,07671 & 6,00000 & 8484 & 0,00105 & $-0,04398$ & 0,00000 \\
\hline 8509 & $\mathbf{0 , 0 7 7 3 5}$ & 7,15830 & 8509 & 0,00064 & $-0,04398$ & 0,00000 \\
\hline 8567 & $\mathbf{0 , 0 7 7 3 5}$ & 8,15830 & 8567 & 0,00000 & $-0,04398$ & 0,00000 \\
\hline 8591 & $\mathbf{0 , 3 1 5 8 9}$ & 9,16429 & 8591 & $\mathbf{0 , 2 3 8 5 4}$ & $-0,04398$ & $-0,00032$ \\
\hline 8615 & 0,36674 & 10,16429 & 8615 & 0,05086 & $-0,04398$ & $-0,00007$ \\
\hline 8660 & 0,41728 & 11,16429 & 8660 & 0,05054 & $-0,04398$ & $-0,00008$ \\
\hline 8699 & 0,46782 & 12,16429 & 8699 & 0,05054 & $-0,04398$ & $-0,00009$ \\
\hline 8735 & 0,57622 & 13,16429 & 8735 & 0,10841 & $-0,04398$ & $-0,00461$ \\
\hline 8756 & 0,57622 & 14,16429 & 8756 & 0,00000 & $-0,04398$ & 0,00000 \\
\hline 8780 & 0,64146 & 15,16429 & 8780 & 0,06523 & $-0,04398$ & $-0,00029$ \\
\hline 8826 & 0,64146 & 16,16429 & 8826 & 0,00000 & $-0,04398$ & 0,00000 \\
\hline 8850 & 0,64262 & 17,16429 & 8850 & $\mathbf{0 , 0 0 1 1 6}$ & $-0,04398$ & 0,00000 \\
\hline 8900 & 0,64262 & 18,16429 & 8900 & 0,00000 & $-0,04398$ & 0,00000 \\
\hline 8924 & 0,64658 & 19,16429 & 8924 & 0,00396 & $-0,04398$ & 0,00000 \\
\hline 8949 & 0,79769 & 20,17328 & 8949 & 0,15111 & $-0,04398$ & $-0,00019$ \\
\hline 8995 & 0,91598 & 21,26571 & 8995 & $\mathbf{0 , 1 1 8 3 0}$ & $-0,04398$ & $-0,00068$ \\
\hline 9017 & 1,18346 & 22,26728 & 9017 & 0,26748 & $-0,04398$ & 0,00015 \\
\hline 9067 & 1,18368 & 23,26728 & 9067 & 0,00022 & $-0,04398$ & 0,00000 \\
\hline 9091 & 1,19567 & 24,26728 & 9091 & 0,01198 & $-0,04398$ & 0,00001 \\
\hline 9115 & 1,25224 & 25,30978 & 9115 & $\mathbf{0 , 0 5 6 5 7}$ & $-0,04398$ & 0,00004 \\
\hline 9243 & 1,30394 & 26,32879 & 9243 & $\mathbf{0 , 0 5 1 7 0}$ & $-0,04398$ & 0,00004 \\
\hline 9256 & 1,30543 & 27,32994 & 9256 & 0,00149 & $-0,04398$ & 0,00000 \\
\hline 9338 & 1,30556 & 28,32994 & 9338 & 0,00013 & $-0,04398$ & 0,00000 \\
\hline 9362 & 1,30635 & 29,33121 & 9362 & $\mathbf{0 , 0 0 0 8 0}$ & $-0,04398$ & 0,00001 \\
\hline 9386 & 1,30681 & 30,33121 & 9386 & $\mathbf{0 , 0 0 0 4 5}$ & $-0,04398$ & 0,00000 \\
\hline
\end{tabular}

Parametr ,a““ wyznaczono na podstawie zależności (12). 


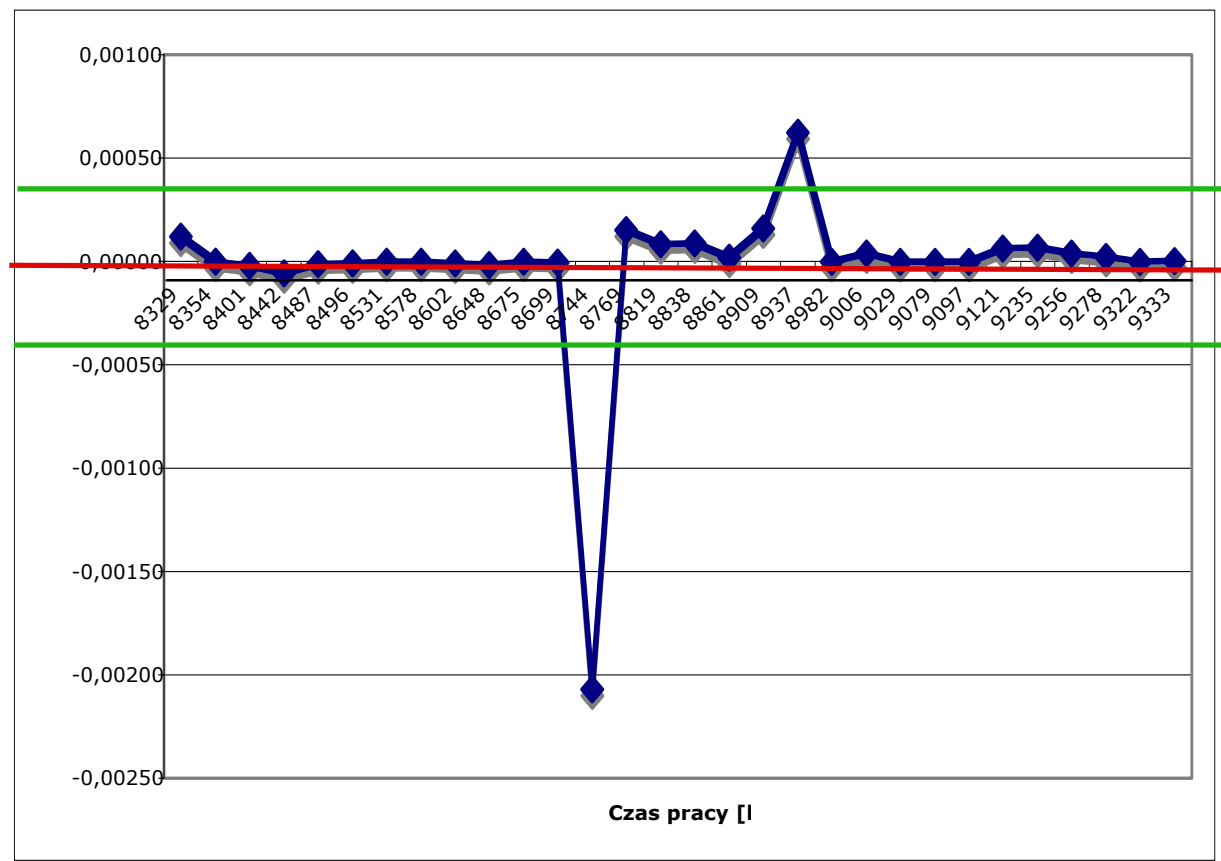

Rys. 1. Przebieg parametru „a“ zespołu pompowego $\mathrm{nr} 3 \mathrm{z}$ uwzględnieniem odchylenia standardowego.

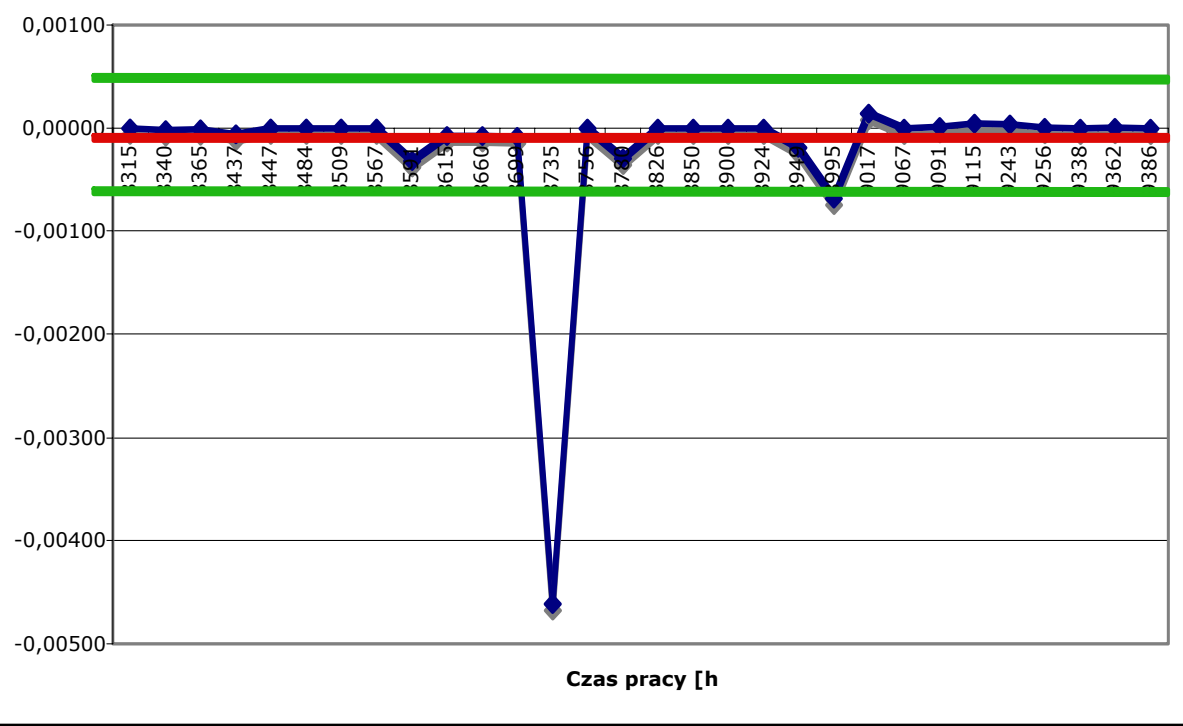

Rys. 2. Przebieg parametru ,a“ zespołu pompowego $\mathrm{nr} 4 \mathrm{z}$ uwzględnieniem odchylenia standardowego. 


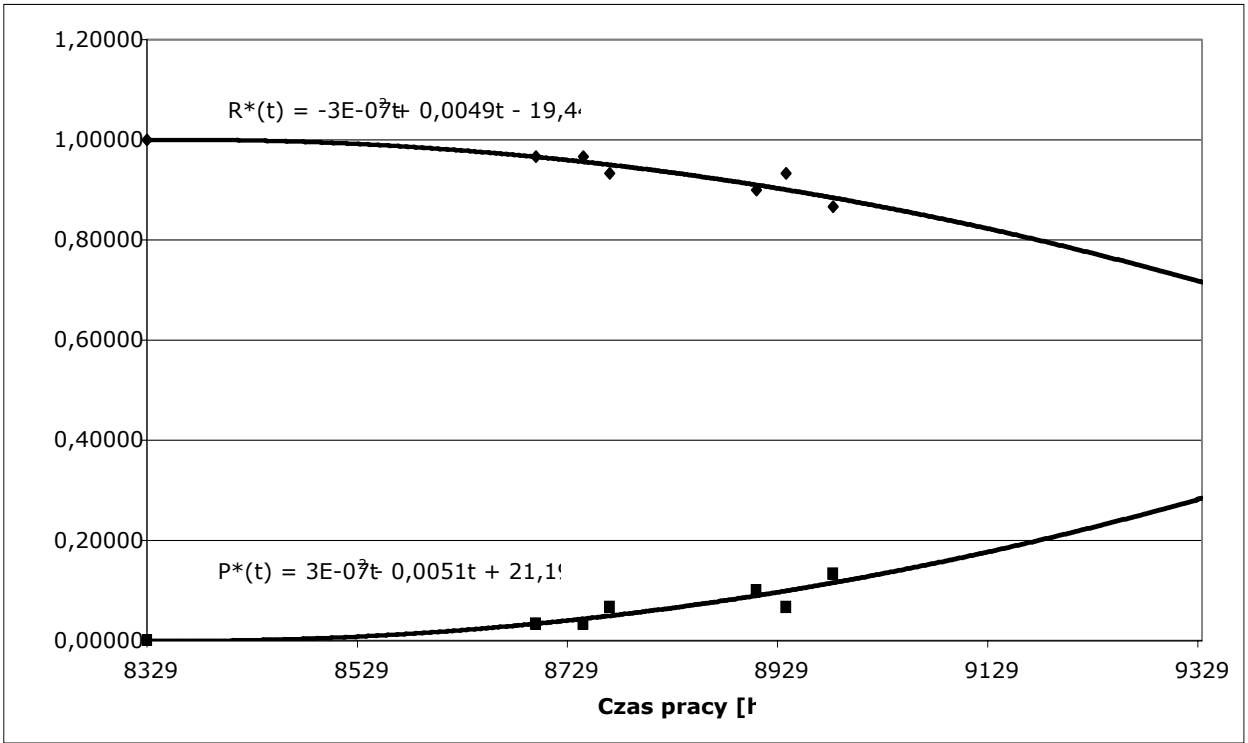

Rys. 3. Przebieg prawdopodobieństwa niepoprawnej pracy $\mathrm{P}^{*}(\mathrm{t})$ oraz przebieg prawdopodobienstwa poprawnej pracy $\mathrm{R}^{*}(\mathrm{t})$ zespołu pompowego nr 3.

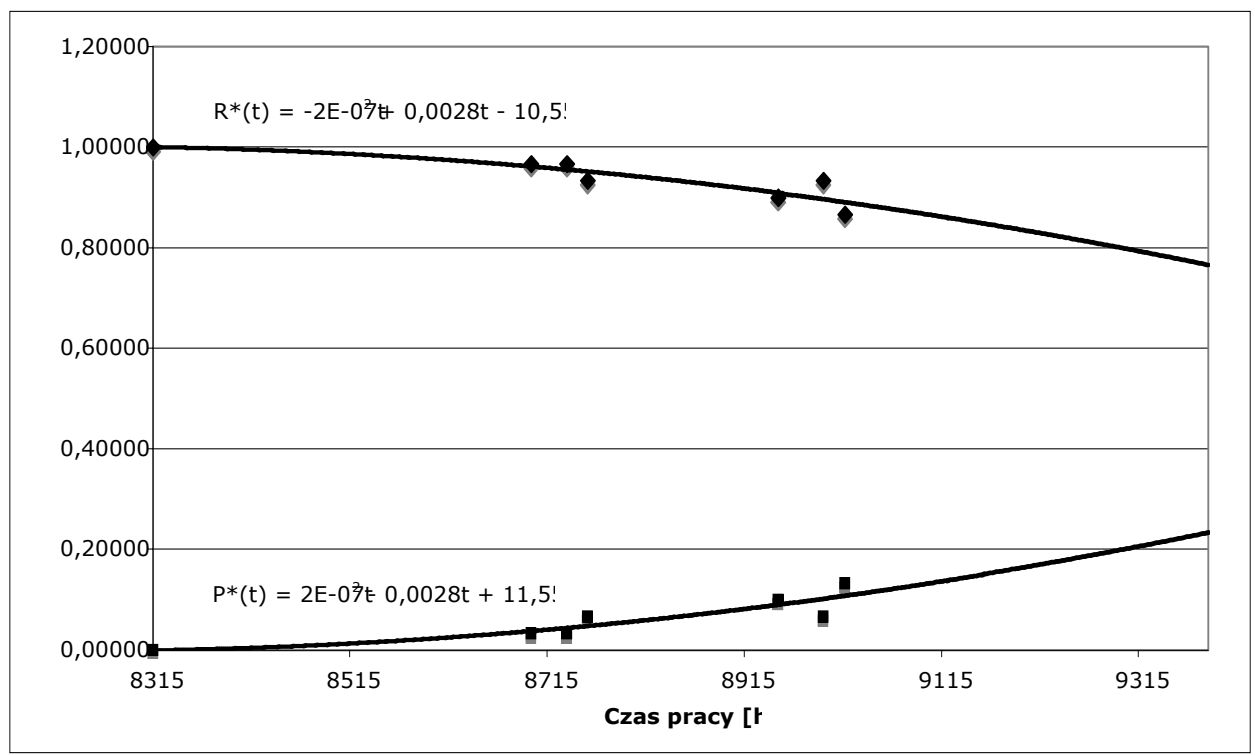

Rys. 4. Przebieg prawdopodobieństwa niepoprawnej pracy $\mathrm{P}^{*}(\mathrm{t})$ oraz przebieg prawdopodobienstwa poprawnej pracy $\mathrm{R}^{*}(\mathrm{t})$ zespołu pompowego nr 4. 
Metoda predykcji charakterystyk niezawodnościowych....

$\mathrm{Na}$ podstawie rys. 3 i 4 stwierdza się, że stan niezawodnościowy i zawodnościowy zespołu pompowego nr 3 i 4 jest podobny. Rożnice są minimalne, ponieważ zespoły te są użytkowane identycznie, tj. oba pracują naprzemiennie po 24 godziny.

\section{Podsumowanie}

Charakterystyki niezawodnosciowe są bardzo ważną informację decydującą o stanie zdatności obiektu. Metody ich wyznaczania są problemem ciagle otwartym szczególnie wtedy, gdy obsługa techniczna nie dysponuje pełną informacją o uszkodzeniach katastroficznych, parametrycznych i przemijających. [7] W artykule przedstawiono nowatorski sposób wykorzystania informacji diagnostycznej (przedstawionej w postaci „liczb przekroczeń progów diagnostycznych" sygnałów użytkowych, otoczenia i towarzyszących [4]) do wyznaczenia charakterystyk niezawodnościowych. Przedstawiona metoda jest bardzo praktyczna bo pozwala weryfikować charakterystyki niezawodnosciowe bez wiadomości o zaistniałych uszkodzeniach katastroficznych, które w procesie eksploatacji nie mogą $\mathrm{w}$ czystej formie wystapić. Wyznaczone charakterystyki niezawodnościowe należy analizować zgodnie $\mathrm{z}$ zasadami diagnostyki tj. $\mathrm{W}$ powiązaniu $\mathrm{z}$ charakterystykami danego obiektu $\mathrm{w}$ przeszłości i $\mathrm{z}$ charakterystykami niezawodnościowymi innych obiektów tego samego typu.

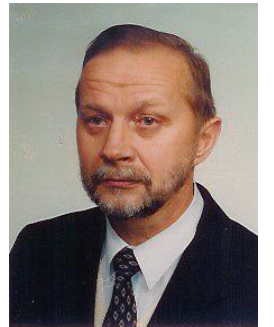

Paweł Lindstedt Ph.D. D.Sc., professor of the Białystok Technical University, associate professor of the Air Force Technical Institute. Research subjects: Construction and utilisation of machines, applied automatics, diagnostics and reliability of machines. His works concern diagnostics of aircraft engines, hydraulic systems, and bearing systems with functional, vibro-acoustic and wear methods.

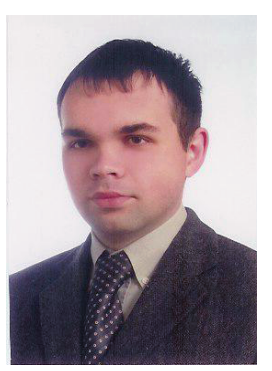

Tomasz Sudakowski M.E., doctoral student of the Department of Mechanical Engineering at the Białystok Technical University. Research subjects: technical diagnostics of bearing systems in aircraft engines, prediction of reliability of technical objects and pumping units based on research of paramteric and transient defects. 
